\title{
The Repair of Complex Neuronal Circuitry by Transplanted and Endogenous Precursors
}

\author{
Jason G. Emsley, Bartley D. Mitchell, Sanjay S. P. Magavi, Paola Arlotta, and \\ Jeffrey D. Macklis
}

Massachusetts General Hospital/Harvard Medical School Center for Nervous System Repair, Departments of Neurosurgery and Neurology, and Program in Neuroscience, Harvard Medical School, Massachusetts General Hospital,

Boston, Massachusetts 02114

\begin{abstract}
Summary: During the past three decades, research exploring potential neuronal replacement therapies has focused on replacing lost neurons by transplanting cells or grafting tissue into diseased regions of the brain. However, in the last decade, the development of novel approaches has resulted in an explosion of new research showing that neurogenesis, the birth of new neurons, normally occurs in two limited and specific regions of the adult mammalian brain, and that there are significant numbers of multipotent neural precursors in many parts of the adult mammalian brain. Recent advances in our understanding of related events of neural development and plasticity, including the role of radial glia in developmental neurogenesis, and the ability of endogenous precursors present in the adult brain to be induced to produce neurons and partially repopulate brain regions affected by neurode-
\end{abstract}

generative processes, have led to fundamental changes in the views about how the brain develops, as well as to approaches by which transplanted or endogenous precursors might be used to repair the adult brain. For example, recruitment of new neurons can be induced in a region-specific, layerspecific, and neuronal type-specific manner, and, in some cases, newly recruited neurons can form long-distance connections to appropriate targets. Elucidation of the relevant molecular controls may both allow control over transplanted precursor cells and potentially allow for the development of neuronal replacement therapies for neurodegenerative disease and other CNS injuries that might not require transplantation of exogenous cells. Key Words: Neurogenesis, neocortex, neural precursors, neural stem cells, neural transplantation, neuronal recruitment.

\section{INTRODUCTION}

Neuronal replacement therapies are based on the idea that neurological function lost to injury or neurodegenerative disease might be improved by introducing new cells that can differentiate and integrate appropriately to replace the function of lost neurons. New cells could theoretically achieve this goal in one of two general ways. ${ }^{1-3}$ New neurons can anatomically integrate into the host brain, become localized to the diseased portion of the brain, receive afferent input, express appropriate neurotransmitters and receptors, and form precise axonal projections. Such neurons would therefore function by integrating into the microcircuitry of the nervous system and replacing lost neurons. Alternatively, newly introduced cells could more simply constitutively secrete neurotrans-

Address correspondence and reprint requests to Jeffrey D. Macklis, MGHHMS Center for Nervous System Repair, Edwards 410, 50 Blossom Street, Boston, MA 02114. E-mail: jeffrey_macklis@hms.harvard.edu. mitters or neurotrophic factors into local CNS tissue, or they could be engineered to produce growth factors to support the survival or regeneration of existing neurons. Growing knowledge about the normal role of endogenous neural precursors, their potential differentiation fates, and their responsiveness to a variety of cellular and molecular controls also suggests that neuronal replacement therapies based on manipulation of endogenous precursors either in situ or ex vivo might be possible.

Neuronal replacement therapies based upon the manipulation of endogenous precursors in situ might have advantages over transplantation-based approaches, but they could have several limitations as well. The most obvious advantage of manipulating endogenous precursors in situ is that there is no need for external sources of cells. Cells for transplantation are generally derived from embryonic tissue, nonhuman species (xenotransplantation), or cells grown in culture. The use of embryonicderived tissue aimed at treating human diseases is com- 
plicated by limitations in tissue availability, as well as by serious political and ethical concerns. Xenotransplantation of animal cells carries the risk of introducing novel diseases into humans, and might be limited by how well xenogenic cells can integrate into the human brain. In many cases, cultured cells must be immortalized by oncogenesis or released from some proliferation control by mitogens, increasing the risk that such cells could become tumorigenic. In addition, transplantation of cells from many of these sources risks immune rejection and may require immunosuppression, if they are not derived from the recipient.

However, there are also potential limitations to the manipulation of endogenous precursor cells as a neuronal replacement therapy. First, such an approach might be limited to particular regions of the brain, because multipotent neural precursors are more densely distributed in particular subregions of the adult brain, such as the subventricular zone (SVZ) and hippocampal subgranular zone. In some cases, it is possible that there simply might not be sufficient numbers of precursor cells to bring about functional recovery. In addition, the potential differentiation fates of endogenous precursors might be too limited to allow their integration into varied portions of the brain. Another potential difficulty is that it could be difficult to provide the precise combination and sequence of molecular signals necessary to induce endogenous precursors to proliferate efficiently and differentiate precisely into appropriate types of neurons deep in the brain. It is currently unknown whether adultborn neurons derived from endogenous precursors undergo the same developmental sequence of events as neuroblasts in the developing brain.

In this review, we will discuss both transplanted and endogenous sources of cells for the repair of complex neural circuitry. We begin with a brief historical review of transplantation studies, which themselves have set the stage for modern studies of directed neuronal replacement strategies. We provide a survey of the use of neural transplantation in a variety of disease paradigms, and also discuss transplantation as an effective tool for rigorous developmental studies. We then present and discuss a biophysical approach for inducing selective apoptosis of specific neuronal populations, and then go on to describe how this model can be used in studies of how transplanted cells, such as multipotent neural precursors or more phenotypically committed cells, can undergo directed migration, differentiation, and the establishment of specific projections. After this discussion of the efficacy of transplanted cells for the repair of complex circuitry, we present a discussion of the phenomenon of adult mammalian neurogenesis and describe the behavior of cells within several key regions in which new neurons are constitutively produced. The use of endogenous sources of cells for directed CNS repair clearly requires a detailed understanding of the identity of adult multipotent neural precursors, as well as an understanding of the ability, or inability, of neural and non-neural cells to undergo phenotypic transdifferentiation. We follow this discussion with a description of how specific targeted manipulation of the neocortical environment can lead to the endogenous production of new neurons, capable of limited re-establishment of complex cortical circuitry. These studies now allow for the development of systematic studies that attempt to understand the molecular signals that might underlie the integration of both transplanted and endogenously derived cells. This review then concludes with a discussion of what the future prospects might be for the development of endogenous repair strategies in the adult CNS.

\section{HISTORICAL PERSPECTIVE}

In 1890, W.G. Thompson made the first serious attempts at grafting neural tissue into the mammalian brain. ${ }^{5}$ In these early studies, Thompson, working with adult cats and dogs, grafted tissue to and from the neocortex and found that the tissue did not completely degenerate but remained recognizable as "brain substance" for up to 7 weeks after transplantation. Later, Tello ${ }^{6}$ demonstrated that regeneration in the CNS of adult rodents, for example, could be facilitated by grafting pieces of peripheral nervous system into the lesioned neocortex, suggesting that adult neurons had the potential to regenerate. In addition, Ranson ${ }^{7}$ showed that rat spinal ganglion cells grafted to slits in the cerebral cortex of a different adult rat recipient could establish extensive neurite growth, suggesting that the environment of the CNS is not absolutely inhibitory to neurite growth. Dunn and others showed that the viability and growth of transplanted neocortical tissue in rats was greatly enhanced when the donor tissue and/or recipient animals were embryonic or neonatal. ${ }^{8}$

\section{MODERN TRANSPLANT STUDIES}

Despite early advances made by grafting neural tissue to or from the neocortex, neural transplantation as a potential method for CNS repair fell out of vogue between the 1920s and 1960s. In the early 1970s, at least two independent groups, for example those of Björklund ${ }^{9}$ and Das, ${ }^{10}$ initiated a more systematic approach to neural transplantation and began exploring its potential as a therapy for motor abnormalities associated with Parkinson's disease. ${ }^{11}$ The shift in emphasis from attempting to analyze the gross viability and growth characteristics of grafted neural tissue, to its potential utility as a therapy for neurodegenerative disease, brought with it a shift toward more detailed studies of transplantation into basal ganglia-related structures, such as the substan- 
tia nigra and striatum. The ideas motivating these studies were to establish a therapeutic paradigm for the seemingly most anatomically localized neurodegenerative disorders, Parkinson's and Huntington's diseases.

\section{NEURAL TRANSPLANTATION FOR DEVELOPMENTAL STUDIES}

In addition to its potential utility in studies of neurodegeneration, neural transplantation has also been employed to advantage as a powerful experimental tool for developmental studies. In many of these studies, cortical tissue has been transplanted in two main paradigms: 1) whole blocks of embryonic cortical tissue have been removed and transplanted into heterotopic cortical areas to examine spatial predetermination and plasticity, ${ }^{12-14}$ and 2) cortical tissue has been transplanted heterochronically (from one developmental stage into either a younger or older stage) to examine the stage specificity and determination of brain areas during development. ${ }^{15-17}$ Not only have these developmental studies examined the plasticity of neural tissue during development, but they have also investigated the effects of intrinsic versus extrinsic influences on the survival, growth, and integration of transplanted neural precursors and stem cells.

Although the transplantation of whole blocks of neural tissue is not currently considered to be a feasible approach for reconstructing complex circuitry within the CNS, these developmental studies have nevertheless provided a valuable resource for approaching potential future therapies involving the transplantation of precursor and stem cells. Indeed, developmental studies have proven extremely important for guiding potential therapeutic strategies that may involve cell transplantation. In particular, such studies can provide critical insight into our understanding of what stage of cells is most appropriate for a particular use, what environmental influences can be expected from the host at a particular age, as well as what factors may need to be extrinsically added or inhibited in the adult CNS to maximize the efficacy of transplanted or endogenous precursors.

The numerous areas of the adult mammalian neocortex are anatomically characterized by their patterns of hierarchical connectivity with both cortical and subcortical structures, as well as by their ability to respond functionally to various inputs from these areas. The timing of neurogenesis during cortical development is highly correlated with neuronal laminar position and subsequent connectivity. ${ }^{16-19}$ During the early formation of the neocortex, however, patterns of neuronal connectivity may not be as well determined as in the adult and, in fact, a considerable amount of epigenetic plasticity appears to exist, in part because of local axonal guidance cues, transient targeting, and axonal elimination. For ex- ample, the host environment appears to control layer $\mathrm{V}$ projections as well as thalamocortical projection patterns in transplanted occipital and somatosensory cortex. ${ }^{12,20}$ Additionally, some studies have demonstrated crossmodal plasticity in the developing cortex, whereby auditory cortex can be induced to receive visual thalamic inputs and exhibit functional properties characteristic of visual cortical areas. ${ }^{21-23}$ Some have interpreted these data as indicating that the early mammalian neocortex lacks specification, and can thus be molded almost entirely by environmental interactions. However, a growing body of evidence suggests that there is also, in fact, a molecular specification of cortical areas, based on the timing of neurogenesis as well as the area in which neurons are born. ${ }^{24}$

\section{A SELECTIVE MODEL OF CORTICAL NEURON DEATH}

Cortical transplantation studies focused on the reconstruction of cortical circuitry following stroke or trauma in adult mammals have shown only modest success using embryonic cortical donor tissue. ${ }^{25-29}$ Some studies have reported small amounts of reciprocal connectivity between the host and the graft; however, this connectivity has been limited, and largely nonspecific. Several factors, including glial scarring, immune interactions, inflammation, and secondary excitotoxicity are likely to have contributed to the failure of cortical transplants to reconstruct the complex laminar, morphological, synaptic, and functional properties of cortical circuitry.

It is clear that reconstruction of neocortical circuitry, or any neural circuitry for that matter, either by transplantation of neural precursors or by manipulation of endogenous precursors, may depend critically upon both local microenvironmental control signals and the intrinsic competence of populations of precursors to respond appropriately to external molecular controls. In contrast to traditional stroke and trauma models that have used cortical transplantation, our lab has developed a model of targeted cortical neurodegeneration in which specific populations of cortical projection neurons can be selectively eliminated, without glial scarring, inflammation, adverse immune reaction, or excitotoxicity. Using this model, which will be described in greater detail below, we found that not only are transplanted immature neuroblasts capable of migrating specifically to laminae undergoing targeted neurodegeneration, but these cells can also undergo correct morphological differentiation, form long-distance projections to appropriate cortical target areas, and integrate synaptically. ${ }^{30-37}$

Furthermore, the efficiency of neuroblast migration and integration into the adult cortex is significantly influenced by the age of the transplantation cell source. For example, donor cells derived from various ages of mouse 
neocortex were compared in a series of transplantation studies, and it was found that later-stage neuroblasts and region-specific immature neurons transplanted into the adult cortex undergoing targeted neurodegeneration develop a mature cortical projection neuron phenotype and make appropriate connections with recipient circuitry with increased efficiency. ${ }^{36,38}$ However, when using transplant cell sources derived from postnatal stages of development, limitations in survival can outweigh this increased efficiency. Taken together, these findings support a progressive sequence of neural precursor differentiation and a spectrum of competence by precursors to respond to instructive microenvironmental signals. Indeed, these results might also suggest that more differentiated precursors might be more advantageous than less differentiated, less committed "stem cells" in certain neural repair strategies.

Targeted apoptotic neurodegeneration produces highly specific cell death of selected types of projection neurons within defined regions of neocortex. Very briefly, cellular degeneration results from the photoactivation of retrogradely transported nanospheres carrying the chromophore chlorin $e_{6}$, stored nontoxically within neuronal lysosomes. ${ }^{32,34,35}$ Chlorin $e_{6}$ produces the reactive oxygen species singlet oxygen only when excited by nearinfrared light; this light penetrates deeply through nervous system tissue without absorption or cellular injury to nontargeted cells. Targeted neurons die by apoptosis via a cascade of well defined and characteristic apoptotic cellular events: biochemical (e.g., internucleosomal DNA fragmentation), morphological (e.g., nuclear fragmentation, specific TUNEL and PI labeling, apoptotic body formation, phagocytic removal of membranebound fragments), ultrastructural (e.g., heterochromatin condensation, apoptotic body formation), and transcriptional. ${ }^{31,34}$ Death depends on both new protein synthesis and intrinsic endonuclease activity. Only neurons both selectively labeled with the chromophore and in the controlled light path undergo apoptotic degeneration that is progressive over a 2- to 3-week period. Intermixed neurons, glia, axons, and connective tissue are not injured. ${ }^{32,39}$

We have applied this approach of targeted apoptotic neuronal degeneration to study cellular and molecular influences over migration and differentiation of newly incorporated neurons. As will be discussed in more detail below, the photoactivated induction of cell death in neocortical pyramidal neurons affects migration and differentiation of transplanted neurons ${ }^{32,33,35,37,40}$ as well as transplanted neural precursors. ${ }^{41}$ An optimal model for cortical repopulation should reflect the intricate interconnections of those neurons that have degenerated. Selective apoptotic neuronal death is postulated to play a role in a variety of neurodegenerative processes. In summary, this model of targeted apoptotic neurodegeneration is well characterized ${ }^{32-35}$ and provides a highly controllable model of apoptotic neuronal death in neocortex. The following sections discuss how transplanted embryonic neurons can exhibit directed migration and differentiation when transplanted into cortex undergoing targeted apoptosis, how such transplanted neurons can re-form specific projections, and how multipotent neural precursors can undergo similar directed neocortical neuronal differentiation.

\section{TRANSPLANTED EMBRYONIC NEURONS UNDERGO DIRECTED MIGRATION AND DIFFERENTIATION IN JUVENILE AND ADULT MICE}

In studies using juvenile and adult mice, we demonstrated at both light and electron microscopic (EM) levels that transplanted embryonic day 17 (E17) and E14 neurons undergo directed, long-distance migration of up to $700-800 \mu \mathrm{m}^{32,35,40}$; projection neuron differentiation characterized as including the development of long-distance projections, morphology, and neurotransmitter and receptor expression ${ }^{35-37,39}$; and afferent synapse formation $^{32,36}$ within regions of targeted callosal projection neuron degeneration in lamina II/III. For these and later experiments, we identified the transplanted neuroblasts by combined genetic and double or triple intracellular prelabeling by electron-dense neuron-specific fluorescent nanospheres, PKH lipophilic dye, and ${ }^{3}[\mathrm{H}]$-thymidine. We performed later analysis with immunocytochemical identification by multiple neuron-specific markers. ${ }^{32,35,36}$ The directed cellular events noted above are not seen under a variety of control conditions, including conditions involving transplantation into intact or excitotoxically lesioned cortex, as well as an alternate source of neurons from the cerebellum. ${ }^{32,35,36,40}$ In addition, the differentiation fate of earlier born neurons could be altered; neuroblasts that normally form deep laminae could differentiate into superficial layer neurons with contralateral projections. These experiments demonstrate localization of these events to regions of neuronal degeneration and that such effects were specific to cortical neurons. These results suggested the hypothesis, to be discussed in more detail later in this review, that targeted neuronal apoptosis produces a molecular and cellular environment permissive and instructive for at least partial cellular repopulation via re-expression of developmental signal molecules that guide elements of cortical neuron differentiation. ${ }^{42}$

Directed migration and initial differentiation occurs over approximately 1 to 3 weeks after initiation of projection neuron death. Approximately $45 \%$ of transplanted E17 neurons undergo directed migration and pyramidal neuron differentiation; the rest of the transplanted cells remain at the injection site, surviving 
as small neurons. ${ }^{32,35}$ In one study, neurons were transplanted at the borders of regions undergoing neuronal death and were quantitatively studied for directed migration. ${ }^{32}$ Migrating neurons moved an average of $300 \mu \mathrm{m}$ and as far as $800 \mu \mathrm{m}$ into the adjacent brain regions, whereas control transplantations did not undergo net movement into the regions at all, staying within $40 \mu \mathrm{m}$ of the injection site. Time-lapse video microscopy and digital confocal imaging in living slice cultures also shows that neurons with classic migratory morphologies (leading and trailing processes, elongated cell bodies, saltatory migration) actively migrate obliquely across intact lamina IV and V toward regions undergoing targeted neuronal apoptosis. ${ }^{40}$ This migration occurs along axons and in the presence of transitional radial glia dedifferentiated from recipient astroglia (confirmed by expression of a recipient GFAP reporter transgene) and immunocytochemically identified by re-expression of the RC-2 radial glial surface antigen. ${ }^{40}$ This dedifferentiation does not occur in the absence of targeted neuronal death, without donor cells, or in other control conditions. Two weeks after transplantation, most neurons have completed migration to their new locations, and many extend axons toward the corpus callosum. ${ }^{35,37}$ Over $65 \%$ of the donor neurons accept afferent synaptic input (demonstrated by EM and synaptophysin labeling), they express the correct complement of primarily excitatory neurotransmitters and appropriate neurotransmitter receptors, and they appear to integrate well at the light and ultrastructural levels. ${ }^{32,36,41}$ Together, these results support the hypothesis that apoptotic degeneration of projection neurons induces re-expression of permissive and instructive signals guiding elements of migration and differentiation of donor neurons, and this suggests that other classes of precursors or their progeny could be appropriately directed if precise signals are identified and manipulated.

\section{DONOR NEURONS RE-FORM SPECIFIC PROJECTIONS}

Several sets of our experiments have focused on another central question regarding development of such transplanted neurons. Do they form long-distance axonal projections, and are these connections specific? We performed these experiments in S1 primary somatosensory cortex of adult mice, to use the known connectivity of S1 to allow for analysis of appropriate or alternate distant axonal projections via double retrograde labeling methods. Large numbers of newly differentiated neurons reformed specific callosal projections 6- to $10-\mathrm{mm}$ long over the 6 to 12 weeks following transplantation, ${ }^{37}$ analyzed by retrograde labeling of donor neurons. The efficiency of this anatomic reconnectivity appears to be highly dependent on the stage of the donor neuroblasts (or precursors in other experiments): projections were made by $21-23 \%$ of pooled E17 cortical donor neuroblasts $^{36,37}$; by $10-15 \%$ of earlier stage E14 neuroblasts; by $1-3 \%$ of transplanted multipotent precursors (Leavitt, unpublished observations); and most recently by over $40 \%$ of more uniform, subregionally dissected E19 S1 anlage neuroblasts. ${ }^{38}$ Donor neuroblasts made no nonspecific projections to closer, alternate targets of other nearby populations of S1 neurons, including ipsilateral thalamus, motor cortex, and secondary somatosensory S2 cortex. Our data and other reports ${ }^{43,44}$ provide evidence that neurons or appropriate precursors can support long-distance and at least partially specific axon extension even in the adult mammalian brain, if transplanted into regions undergoing neuronal degeneration without significant inflammation or gliosis. These experiments set the stage for future experiments in which functional connectivity can be tested.

The observations that axonal outgrowth by embryonic neurons occurs through adult corpus callosum support the idea that axon outgrowth inhibitors present in mature $\mathrm{CNS}^{43-52}$ do not have an absolutely inhibitory effect. This outgrowth may occur because embryonic neurons do not yet have receptors for myelin-associated inhibitors ${ }^{53,54}$ or because differences in lesion paradigms could account for differences in axon growth (e.g., nonspecific, inflammatory, gliotic lesions ${ }^{55}$ vs minimally traumatic transplants). ${ }^{43,44,54}$

\section{MULTIPOTENT NEURAL PRECURSORS CAN UNDERGO DIRECTED NEOCORTICAL NEURONAL DIFFERENTIATION}

The commitment of individual precursors to particular neuronal identities appears to result from a series of progressively restrictive cellular decisions dependent upon the interaction of precursor lineage and local factors, including interactions with other cells, ECM components, and diffusible factors. ${ }^{15,56-60}$ Although primary embryonic cortical neurons respond to appropriate signals, ${ }^{32,35-37,40}$ fetal tissue poses significant problems related to availability and homogeneity. Expanded and manipulated neural precursors and immature neurons could potentially solve this problem by providing abundant and highly characterized cells at defined stages of differentiation, through specific lineages of interest.

We tested the hypothesis that signals upregulated by targeted apoptotic neurodegeneration could affect the earlier differentiation step of initial neuronal specification by more homogeneous multipotent neural precursors: the cerebellar-derived C17.2 cell line, ${ }^{61,62}$ and the even earlier stage, hippocampal-derived HiB5 line. ${ }^{34,63}$ These experiments also tested the feasibility of neuronal replacement by early-stage neural precursors in regions of neurodegeneration in neocortex, a strategy that could 
lead to manipulation of endogenous multipotent precursors. HiB5 cells were immortalized at an earlier stage of differentiation than were C17.2 cells, expressing in vitro fewer markers of cellular differentiation. ${ }^{33}$ We found, in experiments employing transplantation in utero, that both lines can differentiate into neurons and glia during the embryonic period of neurogenesis in neocortex, confirming their multipotential differentiation competence in cortex. Neither cell line efficiently forms neurons postnatally in neocortex under control conditions, ${ }^{33,41}$ consistent with the developmental completion of cortical neurogenesis. Both cell lines differentiate into glia or fail to differentiate within intact or excitotoxically lesioned postnatal neocortex. The cells presumably do not receive signals for neuronal differentiation postnatally to which they could respond. Together, these experiments further supported the importance of local environmental signals in guiding and restricting neural precursor development.

\section{CONSTITUTIVELY OCCURRING ADULT MAMMALIAN NEUROGENESIS}

Ramon y Cajal has been widely quoted as writing that "in the adult centers the nerve paths are something fixed, ended and immutable. Everything may die, nothing may be regenerated." However, in addition to the use of transplanted cells, such as those from embryonic primary cultures or those derived from multipotent neural precursors, it has recently become clear that there are regions within the CNS that might serve as endogenous sources of cells for directed CNS repair. Until recently, the relative lack of recovery from CNS injury and neurodegenerative disease, and the relatively subtle and extremely limited distribution of neurogenesis in the adult mammalian brain, resulted in the entire field reaching the conclusion that neurogenesis does not occur in the adult mammalian brain. Joseph Altman was the first to use techniques sensitive enough to detect the ongoing cell division that occurs in the adult brain. Using tritiated thymidine as a mitotic label, he published evidence that neurogenesis constitutively occurs in the hippocampus ${ }^{64}$ and olfactory bulb ${ }^{65}$ of the adult mammalian brain. These results were later replicated using tritiated thymidine labeling followed by electron microcopy. ${ }^{66} \mathrm{How}$ ever, the absence of neuron-specific immunocytochemical markers at the time resulted in identification of putatively newborn neurons being made on purely morphological criteria. These limitations led to a widespread lack of acceptance of these results, and made research in the field difficult.

The field of adult mammalian neurogenesis was rekindled in 1992, when it was shown that precursor cells isolated from the forebrain can differentiate into neurons in vitro. ${ }^{67,68}$ These results and technical advances, including the development of immunocytochemical re- agents that could more easily and accurately identify the phenotype of various neural cells, led to an explosion of research in the field. Normally occurring neurogenesis in the olfactory bulb, olfactory epithelium, and hippocampus have now been well characterized in the adult mammalian brain.

\section{OLFACTORY BULB NEUROGENESIS}

The cells contributing to olfactory bulb neurogenesis originate in the anterior periventricular zone and undergo a fascinating and intricate path of migration to reach their final position in the olfactory bulb. Adult olfactory bulb neurogenesis has been most extensively studied in the rodent, with some studies conducted in nonhuman primates $^{69,70}$; there is also in vitro ${ }^{71,72}$ and in vivo ${ }^{73}$ evidence suggesting that such neural precursors exist in humans. Several experiments show that the precursors that contribute to olfactory bulb neurogenesis reside in the anterior portion of the subventricular zone. When retroviruses, ${ }^{74}$ tritiated thymidine, ${ }^{74}$ vital dyes, ${ }^{74,75}$ or virally labeled SVZ cells ${ }^{75,76}$ are microinjected into the anterior portion of the SVZ of postnatal animals, labeled cells are eventually found in the olfactory bulb. Upon reaching the olfactory bulb, these labeled neuroblasts differentiate into olfactory granule and periglomerular interneurons. To reach the olfactory bulb, the neuroblasts undergo tangential chain migration though the rostral migratory stream (RMS) into the olfactory bulb. ${ }^{77,78}$ Once in the olfactory bulb, the neuroblasts migrate radially from the RMS and differentiate into interneurons.

Although neural precursors residing in the SVZ in rodents and in nonhuman primates have been found to undergo chain migration through the rostral migratory stream and into the olfactory bulb, recent evidence in humans has raised the possibility that, despite the presence of progenitors in the SVZ, these cells may not undergo chain migration through the RMS in humans. ${ }^{79}$ Although this evidence in humans is compelling but inconclusive as to the possibility of local olfactory bulb neurogenesis at this time, it underlines the fact that direct comparisons cannot always be made between mice and humans, or even between nonhuman primates and humans. The complexity of the human brain is considerably greater than that of rodents, and the introduction of new neurons into such a complex pre-existing system may be a far more challenging task in humans than in rodents or nonhuman primates.

Of notable interest have been the factors that contribute to the direction of migration of the neuroblasts, as well as factors involved in initiating and controlling migration itself. In vitro experiments show that caudal septum explants secrete a diffusible factor, possibly the molecule $\mathrm{Slit}^{80}$ that repels olfactory bulb neural precursors. ${ }^{81}$ Consistent with the idea that SVZ precursor mi- 
gration is directed by repulsion is the finding that SVZ precursors migrate anteriorly along the RMS even in the absence of the olfactory bulb. ${ }^{82}$ The tangential migration of the cells seems to be at least partially mediated by polysialylated neural cell adhesion molecule, certain integrin subunits, and other factors. ${ }^{80,83-85}$ This may be modified by tenascin and chondroitin sulfate proteoglycans that are located near the SVZ. ${ }^{86}$ Neuroblasts undergoing chain migration along the RMS do not travel along radial glia, although glia may play a role in their migration. Garcia-Verdugo et al ${ }^{87}$ presented anatomical evidence that SVZ neuroblasts migrate within sheaths of slowly dividing astrocytes. However, the astrocyte sheaths may not be necessary for tangential migration, because a great deal of tangential migration occurs in the first postnatal week, before astrocytes can be found in the RMS. ${ }^{88}$ More recent evidence has shown that the olfactory bulb itself provides a secretable factor that acts as a chemoattractant for neuronal precursor cells. ${ }^{89}$ Understanding the factors that contribute to normal SVZ precursor migration could be important in developing approaches to induce such precursors to migrate to injured or degenerating regions of the brain.

\section{OLFACTORY EPITHELIUM NEUROGENESIS}

Sensory neurons in the olfactory epithelium are continually generated in adult rodents. The globose basal cells of the olfactory epithelium divide, differentiate into neurons, and send their axons through the olfactory nerve to the olfactory bulb. ${ }^{90,91}$ Of all the neurons in the mammalian body, olfactory epithelium sensory neurons are most directly exposed to potentially damaging influences, which might help to explain the necessity for their continual replacement. The constant flow of air over the epithelium brings a varying combination of new odorants and potential insults to the olfactory sensory neurons. Despite the precarious position of olfactory receptor neurons, the population of olfactory receptor neurons is preserved, and mammals maintain a fairly consistent sense of smell throughout life.

Neurogenesis in the olfactory epithelium is strongly modulated by neuronal death in the epithelium. Olfactory nerve lesions or olfactory bulb lesions, which lead to the degeneration of axotomized neurons, ${ }^{92,93}$ result in an increase in proliferation of precursors. ${ }^{90,92-95}$ The new neurons that form in the adult olfactory epithelium send axons through the olfactory nerve and into the mature olfactory bulb. ${ }^{96,97}$ The ability of the newborn neurons to re-form long-distance projections is probably due to their immature state and to the environment through which they extend their axons.

In vitro experiments suggest that mature olfactory sensory neurons produce a signal that inhibits neurogenesis. Olfactory epithelial precursor cells undergo dramatically reduced neurogenesis in the presence of mature olfactory receptor neurons in vitro, ${ }^{98}$ suggesting that when olfactory sensory neurons are lost in vivo, the factors inhibiting neurogenesis are reduced, allowing the formation of new sensory neurons. Understanding the signals that inhibit neurogenesis and neuronal integration could be as important as understanding the signals that foster neurogenesis. Research in the olfactory epithelium highlights the role of inhibitory factors in controlling neurogenesis; understanding such signals in degenerating portions of the CNS will be instrumental in developing neuronal replacement therapies.

\section{HIPPOCAMPAL NEUROGENESIS}

Neurogenesis in the adult mammalian hippocampus has been extensively studied, at least partially because of the tantalizing connection between the hippocampus and the formation of memory. Of particular interest is the fact that hippocampal neurogenesis can be modulated by physiological and behavioral events such as aging, stress, seizures, learning, and exercise. These properties of hippocampal neurogenesis may provide novel methods for studying neurogenesis and may help to elucidate broader influences that may be relevant to neuronal replacement therapies.

Hippocampal neurogenesis has been described in vivo in adult rodents, ${ }^{64}$ monkeys, ${ }^{99-101}$ and humans. ${ }^{102}$ Newborn cells destined to become neurons are generated along the innermost aspect of the granule cell layer, the subgranular zone, of the dentate gyrus of the adult hippocampus. The cells migrate a short distance into the granule cell layer, send dendrites into the molecular layer of the hippocampus, and send their axons into the CA3 region of the hippocampus. ${ }^{103-105}$ Adult-born hippocampal granule neurons are morphologically indistinguishable from surrounding granule neurons, ${ }^{106}$ and they develop electrophysiological properties characteristic of mature neurons. ${ }^{107}$ The precursor cells appear to mature rapidly, and extend their processes into the CA3 region as early as 4 days after division. ${ }^{104}$ The properties of both the precursor cells and the hippocampal environment likely contribute to the rapid maturation observed.

Much research on hippocampal precursors has been performed in vivo, but many in vitro results are also useful for understanding the effects of growth factors on the differentiation of hippocampal precursors. Hippocampal precursor cells are studied in vitro much like SVZ precursors: they are removed from the brain, dissociated, and typically cultured in EGF and/or FGF-2; the mitogen is then removed, and the cells are exposed to the growth factors of interest. Hippocampal precursors proliferate in response to FGF-2 and can differentiate into astroglia, oligodendroglia, and neurons in vitro. ${ }^{106}$ 
BDNF increases both neuronal survival and differentiation, while NT-3, NT-4/5, and CNTF might have more limited effects. ${ }^{108}$ Further demonstrating the existence of precursors in the adult human, multipotent precursors derived from the adult human brain can be cultured in vitro. ${ }^{109,110}$

Hippocampal neurogenesis occurs throughout adulthood but declines with age. ${ }^{111}$ This age-related decline could be because of a depletion of multipotent precursors with time, a change in precursor cell properties, or a change in the levels of molecular factors that influence neurogenesis. Understanding what causes this age-related decrease in neurogenesis may be important in assessing the potential utility of potential future neuronal replacement therapies based on manipulation of endogenous precursors. Although aged rats have dramatically lower levels of neurogenesis than younger rats, adrenalectomized aged rats have levels of neurogenesis very similar to those of young adrenalectomized rats. ${ }^{112,113}$ These results suggest that it is, at least partially, increased corticosteroids, which are produced by the adrenal glands, and not a decrease in the number of multipotent precursors, that leads to age-related decreases in neurogenesis. At least in the hippocampus, multipotent precursors appear to survive with advancing age.

Seizures can also increase hippocampal neurogenesis. However, it appears that seizure-induced neurogenesis may contribute to inappropriate plasticity, highlighting the fact that newly introduced neurons need to be appropriately integrated into the brain to have beneficial effects. Chemically or electrically induced seizures induce the proliferation of subgranular zone precursors, the majority of which differentiate into neurons in the granule cell layer. ${ }^{114,115}$ However, some newborn cells differentiate into granule cell neurons in ectopic locations in the hilus or molecular layers of the hippocampus and form aberrant connections to the inner molecular layer of the dentate gyrus, in addition to the CA3 pyramidal cell region. ${ }^{15,116}$ It is hypothesized that these ectopic cells and aberrant connections may contribute to hippocampal kindling. ${ }^{117,118}$

Hippocampal cell death or activity-related signals resulting from seizures may modify signals that lead to increased neurogenesis. Induced seizures lead to degeneration of hippocampal neurons, ${ }^{119-121}$ which is followed by neurogenesis. ${ }^{114,115}$ Excitotoxic or physical lesions of the hippocampal granule cell layer induce precursor cell proliferation within the dentate gyrus and the formation of neurons that have the morphological and immunocytochemical properties of granule cell neurons. ${ }^{122}$ These results suggest that hippocampal granule cells either inhibit neurogenesis, as do neurons in the olfactory epithelium, or that they or surrounding cells produce signals that induce neurogenesis as they die. However, since neurogenesis is also increased by less pathological levels of electrophysiological activity, ${ }^{123}$ it is also possible that signals induced by such activity play a role in seizure-induced hippocampal neurogenesis.

Events occurring in the hippocampus dramatically demonstrate that behavior and environment can have a direct influence on the microcircuitry of the brain. Animals living in an enriched environment containing toys, running wheels, and social stimulation contain more newborn cells in their hippocampus than do control mice living in standard cages. ${ }^{124}$ Experiments to further assess which aspects of the enriched environment contribute to increased neurogenesis reveal that a large portion of the increase can be attributed simply to exercise via running. ${ }^{125,126}$ Associative learning tasks that involve the hippocampus also appear to increase neurogenesis. ${ }^{127}$ Stress, on the other hand, can reduce neurogenesis in both rodents ${ }^{128,129}$ and primates. ${ }^{99}$ An intriguing, but completely speculative, idea that has been advanced by some in this field is that the processes mediating these effects on neurogenesis may underlie some of the benefits that physical and social therapies provide for patients with stroke and brain injury.

Some of the molecular mechanisms that mediate behavioral influences on hippocampal neurogenesis have begun to be elucidated. For instance, IGF-I, which increases adult hippocampal neurogenesis, ${ }^{130}$ is preferentially transported into the brain in animals that are allowed to exercise. Blocking IGF-I activity in exercising animals reduces hippocampal neurogenesis, suggesting that IGF-I at least partially mediates the effects of exercise on neurogenesis. ${ }^{131}$ Stress increases systemic adrenal steroid levels and reduces hippocampal neurogenesis. ${ }^{129}$ Adrenalectomy, which reduces adrenal steroids, including corticosteroids, increases hippocampal neurogenesis, ${ }^{112,132}$ suggesting that adrenal hormones at least partially mediate the effects of stress on hippocampal neurogenesis. Intriguingly, some antidepressant medications also appear to increase neurogenesis. ${ }^{133-135}$ Together, these results demonstrate that adult neurogenesis can be modified by systemic signals, suggesting that modifying such systemic signals, and not only local ones, may be useful in developing potential future neuronal replacement therapies involving manipulation of endogenous precursors. ${ }^{136}$

Adult hippocampal multipotent precursors can adopt a variety of fates in vivo, suggesting that they may be able to integrate appropriately into neuronal microcircuitry outside of the dentate gyrus of the hippocampus. Hippocampal precursors transplanted into neurogenic regions of the brain can differentiate into neurons, while precursors transplanted into non-neurogenic regions do not differentiate into neurons at all. Adult rat hippocampal precursors transplanted into the rostral migratory stream migrate to the olfactory bulb and differentiate into a neuronal subtype not found in the hippocampus, ty- 
rosine hydroxylase-positive neurons. ${ }^{137}$ However, although adult hippocampal precursors transplanted into the retina can adopt neuronal fates and extend neurites, they do not differentiate into photoreceptors, demonstrating at least conditional limitation of their differentiation fate potential. ${ }^{138,139}$ These findings demonstrate the importance of the local cellular and molecular microenvironment in determining the fate of multipotent precursors. These results also highlight that, although adult hippocampal precursors can adopt a variety of neuronal fates, they may not be able to adopt every neuronal fate.

Some recent correlative evidence suggests that newly generated neurons in the adult hippocampus may participate in some way in hippocampal-dependent memory. Nonspecifically inhibiting hippocampal neurogenesis using a systemic mitotic toxin impairs trace conditioning in a manner not seen in relevant controls, suggesting a role for newly born neurons in the formation of memories. ${ }^{140}$ These correlative results, along with direct analysis of electrophysiologic integration by newborn granule neurons, ${ }^{107}$ suggest that adult-born hippocampal neurons integrate functionally into the adult mammalian brain. Ongoing research in several laboratories is exploring the precise role that new neurons might play in adult hippocampal circuitry.

An interesting, but as yet unproven, hypothesis concerning the role of hippocampal neurogenesis in human depression has been proposed. Jacobs et al. ${ }^{141}$ and others propose that insufficient hippocampal neurogenesis causally underlies depression. ${ }^{135,142}$ Consistent with this hypothesis, stress-related glucocorticoids are associated with a decrease in neurogenesis, and increased serotonin levels ${ }^{141,143}$ or antidepressants ${ }^{134}$ are associated with an increase in neurogenesis. However, the hippocampus is generally thought to be involved in memory consolidation, and less involved in the generation of mood, suggesting that altered hippocampal neurogenesis may be secondary to, rather than causative of, depression.

Although many studies of adult-born progenitor cells in the hippocampus report that adult-born hippocampal precursors residing in the subgranular zone of the dentate gyrus exhibit stem-like properties in vitro, ${ }^{4,144,145}$ these studies often employ dissociation of the entire hippocampus and immediately adjacent subependymal zones. Others have investigated the stem-like properties of neurosphere cultures derived from microdissected subregions of the hippocampus and the surrounding ventricular ependymal areas, and find that hippocampal progenitors residing in the adult dentate gyrus do not exhibit fully stem-like properties, in that they are not capable of selfrenewal after primary spheres are passaged. ${ }^{146}$ In that report, it was shown that subependymal-derived neurospheres are, in fact, the population that is capable of massive self-renewal into at least the second and third passages, and that these cells are the likely source of "stem cells" described in previous studies. Though there is still debate on these issues, one interpretation is that, although specific neurogenic regions in the adult brain may be capable of repopulating specific regions of the brain, these regions may not be more widely capable of producing new neurons for other regions of the adult brain. These and other recent findings discussed below support the hypothesis that quiescent populations of precursor cells exist in the adult brain that, although they are not neurogenic under normal conditions, can proliferate and become neurogenic in response to appropriate signals and/or pathological processes. The possibility for neuronal replacement strategies involving the manipulation of endogenous precursors in the adult brain is, therefore, an area of great interest in the development of potential therapeutic strategies for treating brain injury or degeneration.

\section{CORTICAL NEUROGENESIS}

The vast majority of studies investigating potential neurogenesis in the neocortex of the well studied rodent brain do not report normally occurring, constitutive adult cortical neurogenesis. Our own results demonstrate a complete absence of constitutively occurring neurogenesis in murine neocortex. ${ }^{147}$ However, a few studies report low-level, constitutively occurring neurogenesis in specific regions of the neocortex of adult primates ${ }^{148,149}$ and in the visual cortex of adult rat. ${ }^{66}$ In Gould et al., ${ }^{100}$ neurogenesis of 2-3 new neurons per millimeter cubed was reported in prefrontal, inferior temporal, and posterior parietal cortex of the adult macaque, but not in striate cortex, a presumably simpler primary sensory area. However, these experiments were strikingly confounded by the fact that the areas with the reported exceptionally small number of new neurons had actually been previously lesioned by extracellular recording electrodes, raising the issue of response to local cellular injury and/or death. In contrast, other more recent reports analyzed with more rigorous methods have been unable to reproduce these findings, and report a complete absence of cortical neurogenesis in both rodents and primates. ${ }^{150-152}$ There exists a single report of neurogenesis in the visual cortex of the adult rat, ${ }^{66}$ but this study used tritiated thymidine and purely morphological cell type identification, and has not been confirmed by any other group, including our own. It is unclear whether neurogenesis occurs normally in the neocortex of any mammals, but further examination of potential constitutively occurring neurogenesis in classically non-neurogenic regions ${ }^{153}$ will be required to assess definitively the potential existence of perhaps extremely low-level neurogenesis. 


\section{THE IDENTITY AND POTENTIAL LOCATION OF ADULT MAMMALIAN MULTIPOTENT PRECURSORS}

If adult multipotent precursors were limited to the two neurogenic regions of the brain, the olfactory bulb and hippocampal dentate gyrus, it would severely limit the potential of neuronal replacement therapies based on in situ manipulation of endogenous precursors. However, adult multipotent precursors are not limited to the olfactory epithelium, anterior SVZ, and hippocampus of the adult mammalian brain; they have been cultured in vitro from caudal portions of the SVZ, septum, ${ }^{4}$ striatum, ${ }^{4}$ cortex, ${ }^{154}$ optic nerve, ${ }^{154}$ spinal cord, ${ }^{155,156}$ and retina. ${ }^{157}$ The precursors derived from all these regions can selfrenew and differentiate into neurons, astroglia, and oligodendroglia in vitro. It is thought that they normally differentiate only into glia or die in vivo. Cells from each region have different requirements for their proliferation and differentiation. Precursors derived from septum, striatum, cortex, and optic nerve are reported to require FGF-2 to proliferate and differentiate into neurons in vitro. There are conflicting reports on whether FGF-2 is sufficient to culture spinal cord precursors. ${ }^{155,156}$ Retinal precursors do not require any mitogens to divide in vitro, although they do respond to both EGF and FGF-2. As with all primary cultures, the particular details of the protocols used can strongly influence the proliferation, differentiation, and viability of the cultured cells, so it is difficult to compare results from different labs. It is estimated that adult multipotent precursors can be found in small but significant numbers in various regions of the brain, e.g., separating cortical neural precursors by Percoll gradient yields about 140 multipotent precursors per milligram versus 200 per milligram in the hippocampus. ${ }^{154}$ Understanding the similarities and differences between the properties of multipotent precursors derived from different regions of the brain will be instrumental in potentially developing neuronal replacement therapies based on manipulation of endogenous precursors.

Although it is not generally accepted, there are reports that, in addition to the undifferentiated multipotent precursors that are found in various portions of the brain, mature neurons themselves can be induced to divide. ${ }^{158,159}$ While it seems unlikely that a neuron could maintain the elaborate neurochemical and morphologic differentiation state of a mature neuron while replicating its DNA and remodeling its nucleus and soma, it is still theoretically possible. Although it is generally accepted that other neural cells, such as astroglia, can divide, most reports suggest that any attempt by differentiated neurons to re-enter the cell cycle results in aborted cycling and, ultimately, death. ${ }^{160}$ Significant evidence would need to be presented to demonstrate convincingly that mature neurons in the adult brain are capable of mitosis.
The effort to identify the neural precursors that contribute to olfactory bulb neurogenesis has generated a great deal of controversy. Two potential sources of olfactory bulb neuroblasts have been suggested: a subpopulation of astrocytic-like cells in the subventricular zone, and ependymal cells lining the ventricles. It has been reported that single ependymal cells are capable of producing neurospheres, ${ }^{161}$ free-floating spheres of cultured multipotent neural precursors, neurons, and glia. In contrast, it has also been reported that ciliary ependymal cells form spheres that consist only of astrocytes. ${ }^{162}$ Other investigators have been unable to generate neurospheres from single ciliary ependymal cells, and instead suggest that a population of "transit-amplifying" multipotent neural precursors found in the adult brain are a type of astrocyte, expressing astrocytic morphology and GFAP. ${ }^{163,164}$ Additional independent reports provide support for the concept that multipotent neural precursors with similarities to astrocytes contribute to adult neurogenesis. ${ }^{165}$ Although the majority of currently available evidence suggests that GFAP-expressing cells in the SVZ are a proximal source of olfactory bulb neurogenesis, it is important to distinguish between true astroglia and a distinct class of precursor cells that may also express GFAP. GFAP, although generally a reliable marker for activated astrocytes, has been used as a sole phenotypic marker in reports suggesting that astrocytes are multipotent neural precursors or "stem cells." 166,167 It is quite possible that at least some multipotent neural precursors may also express GFAP, while remaining distinct from astroglia. Further clarifying the identity of potentially multiple classes of multipotent neural precursors that contribute to adult neurogenesis will increase our ability to manipulate such cells.

Although the identity of the adult multipotent neural precursors in the SVZ is still controversial, a number of experiments have been performed to manipulate their fate and examine their potential, both in vitro and in vivo. These results will guide attempts to manipulate endogenous precursors for brain repair. In vitro, subventricular zone precursors have been exposed to a number of factors to determine their responses. Generally, precursor cells have been removed from the brain, dissociated, and cultured in EGF and/or FGF-2. The EGF and/or FGF-2 is then removed, and the cells are exposed to differentiation conditions and/or growth factors of interest. The details of this process, including the particular regions from which the cells are derived, the media in which they are grown, and the substrates on which they are plated, can have significant effects on the fate of the precursors. ${ }^{168}$ EGF and FGF-2 ${ }^{169-171}$ both induce the proliferation of SVZ precursors and can influence their differentiation. EGF tends to direct cells to a glial fate, and FGF-2 more toward a neuronal fate, ${ }^{168}$ while bone morphogenetic proteins promote differentiation of SVZ precursors into 
an astroglial fate. ${ }^{172}$ However, PDGF ${ }^{156,173}$ and IGF- $1^{174}$ promote SVZ precursors to differentiate into neurons. There are conflicting results regarding whether BDNF promotes the survival ${ }^{175,176}$ or differentiation ${ }^{174,177}$ of SVZ precursors in vitro. ${ }^{177}$ Remaining questions notwithstanding, in vitro results show that it may be possible to influence the proliferation and differentiation of adult SVZ precursors.

The effects of several growth factors, neurotrophic factors, and cytokines have also been tested in vivo, to investigate their effects under physiological conditions. Intracerebroventricularly infused EGF or TGF- $\alpha$ induce a dramatic increase in SVZ precursor proliferation, whereas FGF-2 and CNTF induce smaller increases in proliferation. ${ }^{178-180}$ Even subcutaneously delivered FGF-2 can induce the proliferation of SVZ precursors in adult animals. ${ }^{181}$ However, despite the fact that newborn, mitogen-induced cells disperse into regions of the brain surrounding the ventricles, it is generally accepted that none of the newborn cells differentiates into neurons. ${ }^{179}$ Intraventricularly infused BDNF increases the number of newly born neurons found in the olfactory bulbs of adult animals. ${ }^{182}$ Further studies have shown that intraventricularly administered BDNF is not only capable of increasing the proliferation of SVZ precursors, but is additionally able to promote neuronal migration into ectopic areas such as the neostriatum, septum, thalamus, and hypothalamus. ${ }^{183,184}$ These findings indicate that it might be possible to use growth factors to manipulate adult endogenous precursors in vivo to replace neurons lost to diseases or degeneration in brain areas that do not normally undergo neuronal replacement.

Several reports have attempted to establish the differentiation potential of SVZ multipotent precursors, but these studies have yielded conflicting results. Postnatal mouse SVZ precursors can differentiate into neurons in a number of regions in the developing neuraxis, ${ }^{185}$ while their fate is more limited to astroglia when they are transplanted into adult brain. ${ }^{186}$ Adult mouse SVZ precursors injected intravenously into sublethally irradiated mice have been reported to differentiate into hematopoietic cells, interpreted as demonstrating the broad potential of neural precursors for differentiation and interlineage "transdifferentiation." 187 However, it is possible that either cell fusion or a chance transformation of cultured SVZ cells led to a single transformant precursor accounting for this finding. In this event, it could be concluded that this result is not generally the case. However, one report indicates that labeled multipotent neural precursors derived from adult mouse and transplanted into stage 4 chick embryos or developing mouse morulae or blastocysts can integrate into the heart, liver, and intestine, and express proteins specific for each of these sites. ${ }^{188}$ However, it has been again suggested by others in the field that both fusion or transformation could ex- plain some of these results. Adult multipotent neural precursors may not be totipotent, but it appears that they may possibly be capable of differentiating into a wide variety of cell types under appropriate conditions. These results indicate that the local cellular and molecular environment in which SVZ neural precursors are located can play a significant role in their differentiation. Providing the cellular and molecular signals for appropriate differentiation and integration of new neurons will be critical for neuronal replacement therapies in which endogenous neural precursors are either transplanted or manipulated in situ.

\section{THE ROLE OF RADIAL GLIA IN NEUROGENESIS}

The role of radial glia during mammalian CNS development has recently undergone a revision in thinking, such that, in addition to the traditional view of radial glia providing a scaffolding on which newly generated neuroblasts can migrate into the developing cortex, emerging evidence indicates that radial glia are themselves neural progenitors capable of generating neuronal phenotypes specific to several brain regions, including the cortex, striatum, and lateral ganglionic eminence. ${ }^{189-192}$ Some estimate the percentage of cortical pyramidal neurons generated by radial glia to be greater than $90 \% .{ }^{191}$ It is unclear whether the diversity of neuronal subtypes generated by radial glia in the distinct areas of the developing brain are the result of intrinsic diversity of radial glia based on regional prespecification or the chronological regulation of molecular controls over neuronal fate. However, recent findings characterizing the regionspecific differences in both radial glia and astrocytes suggest that cellular and molecular distinctions may lead to a greater understanding of the developmental potential of radial glia to produce distinct classes of neurons in different areas of the developing brain. ${ }^{193-195}$

Radial glia appear to be heterogeneous in terms of the neuronal progeny that they produce, with subsets of radial glia expressing Pax6 in the cortex, ${ }^{193,195}$ retinolbinding protein $1^{25}$ in the developing lateral ganglionic eminence, Olig2 in oligodendrocytes located in the medial ganglionic eminence, ${ }^{189}$ and sonic hedgehog in ventral regions of the developing brain. ${ }^{196}$ Whether radial glia are directly and functionally involved in the patterning of the developing CNS remains to be seen. In addition, the precise role of radial glia, if any, in the adult CNS remains to be elucidated.

\section{HEMATOPOIETIC TRANSDIFFERENTIATION: CELL FUSION OR CELL CONFUSION?}

The ability of non-neural cells to "transdifferentiate" into neurons and other neural cells has become a subject 
of great interest in the past few years. Such transdifferentiation of peripherally available cells appears as an especially enticing prospect for future cell-replacement therapies in the CNS, in light of the readily abundant and renewable sources of such cells, such as bone marrow, blood, skin, and fat. Much of this work has focused on the ability of marrow stromal stem cells (MSCs) to transdifferentiate into neural cell types both in vitro and in vivo. It has been reported that MSCs exposed to growth and/or trophic factors are capable of expressing several neural markers, including nestin, NeuN, trkA, neuronspecific enolase (NSE), neurofilament, and tau protein. ${ }^{197,198}$ Some cells observed in these studies have been thought to exhibit neuronal morphologies in vitro, with long processes, and what have been interpreted to be growth cones and filopodia. Others have interpreted these cells as spindle-shaped cells contracting during the process of cell death. In vivo work with bone marrow cells (BMCs) transplanted or infused into irradiated or hematopoietically deficient mice has been interpreted by some authors as showing donor-derived cells in the brain, expressing the individual neuronal antigens NeuN, NF-H, class III B-tubulin, and NSE. ${ }^{199,200}$ Other claims of transdifferentiation of marrow-derived cells into fully differentiated Purkinje neurons in the adult cerebellum have also been made, ${ }^{201}$ and there have been reports of improved neurological function after transplantation of BMCs in brain injury models. ${ }^{202,203}$

Despite the excitement generated by studies regarding such remarkable developmental plasticity of blood and marrow stromal cells to transdifferentiate into neurons (and other cell types), further investigation of the phenomena observed in the above studies, by the same and additional labs, casts substantial doubt on whether the observations represent transdifferentiation at all. Rather, it appears likely that either cell fusion or the inappropriate expression of multiple cell-type markers (cell "confusion") has led investigators to their conclusions. The expression of one or more neural or neuronal protein markers does not necessarily indicate that a cell is a neural cell or a neuron, respectively, especially if the cell has undergone atypical differentiation from an alternative lineage. It increasingly appears possible that transplanted or cultured marrow cells differentiate aberrantly and express a wide variety of cellular markers, including neural and/or neuronal markers. To substantiate reports of transdifferentiation, it is critical that analyses of neural and/or neuronal differentiation be accompanied by data showing the absence of non-neural or non-neuronal markers. In addition, the presence of defining characteristics of neurons, e.g., classical morphology, axonal projection, dendritic elaboration, synapse formation, neurotransmitter production, and/or generation of action potentials in response to activation could be considered minimal requisites to conclusions regarding neuronal dif- ferentiation. Neurological functional improvements in rodent studies have largely been attributed to release of trophic factors by transplanted cells ${ }^{204,205}$ or to angiogenesis, ${ }^{206,207}$ but not to actual neuronal differentiation and integration of transdifferentiated marrow cells. Several recent studies report that there is little evidence for hematopoietic transdifferentiation, ${ }^{208-211}$ even in response to brain injury, and these studies have further indicated rather convincingly that the phenomena of hematopoietic transdifferentiation into Purkinje neurons, cardiomyocytes, and hepatocytes is actually a result of cell fusion. ${ }^{212,213}$

It is increasingly thought that circulating transplanted microglia are responsible for cell fusion, and thus the misidentification of transgenically tagged transplanted cells as morphologically mature cell types that express neural cell type-specific markers. Although the prospect of bona fide transdifferentiation of marrow cells into neural cells would be exciting, the existing data do not currently support this interpretation. However, the possibility of therapeutic strategies involving the fusion of microglia with mature cell types vulnerable to degeneration, as molecular and/or genetic delivery agents, is a potentially promising field. The genetic manipulation of microglia before transplantation may allow for effective and selective gene or molecular product delivery to degenerating populations of cells via cell fusion.

\section{MANIPULATING THE CORTICAL ENVIRONMENT}

Endogenous multipotent precursors in the adult brain can divide, migrate, differentiate into neurons, receive afferents, and extend axons to their targets. Multipotent precursors are concentrated in the olfactory epithelium, anterior SVZ, and the dentate gyrus of the hippocampus, but they can be found in lower densities in a number of other regions of the adult brain. In addition, these precursors also have a broad potential; they can differentiate into at least three different cell types (astroglia, oligodendroglia, and neurons), given an appropriate in vitro or in vivo environment. These properties of endogenous multipotent precursors led us to explore the fate of these precursors in an adult cortical environment that has been manipulated to support neurogenesis.

As discussed earlier in this review, our lab has previously shown that cortex undergoing synchronous apoptotic degeneration of projection neurons forms an instructive environment that can guide the differentiation of transplanted immature neurons or neural precursors. ${ }^{31,32,34,39,214}$ Immature neurons or multipotent neural precursors transplanted into targeted cortex can migrate selectively to layers of cortex undergoing degeneration of projection neurons, differentiate into projection neurons, receive afferent synapses, express appropriate neurotransmitters and receptors, and re-form 
appropriate long-distance connections to the original contralateral targets of the degenerating neurons in adult murine neocortex. ${ }^{35-38,40-42}$

These results suggested to us that cortex undergoing targeted apoptotic degeneration could direct endogenous multipotent precursors to integrate into adult cortical microcircuitry. In agreement with this hypothesis, we found, for the first time, that endogenous multipotent precursors, normally located in the adult brain, can be induced to differentiate into neurons in the adult mammalian neocortex without transplantation. ${ }^{147} \mathrm{We}$ induced synchronous apoptotic degeneration of corticothalamic neurons in layer VI of anterior cortex and examined the fates of dividing cells within cortex, using BrdU and markers of progressive neuronal differentiation. BrdU+ newborn cells expressed NeuN, a mature neuronal marker, and survived at least 28 weeks, while no new neurons were observed in control, intact cortex. Moreover, some newborn neurons displayed typical pyramidal neuron morphology (large, 10-15 $\mu \mathrm{m}$ diameter somata with apical processes) characteristic of neurons that give rise to long-distance projections. Retrograde labeling from thalamus demonstrated that newborn, BrdU+ neurons can form long-distance, appropriate corticothalamic connections. ${ }^{147}$ Together, these results demonstrate that endogenous neural precursors can be induced in situ to differentiate into cortical neurons, survive for many months, and form appropriate long-distance connections in the adult mammalian brain (FIG. 1). The same microenvironment that supports the migration, neuronal differentiation, and appropriate axonal extension of transplanted neuroblasts and precursors also supports and instructs the neuronal differentiation and axon extension of endogenous precursors. These results demonstrate that the normal absence of constitutive cortical neurogenesis does not reflect an intrinsic limitation of the potential of endogenous neural precursors, but more likely results from a lack of appropriate microenvironmental signals necessary for neuronal differentiation or survival. Elucidation of these signals could enable CNS repair. Taken together, our results demonstrate that endogenous neural precursors can be induced to differentiate into neocortical neurons in a layer- and region-specific manner and re-form appropriate corticothalamic connections in regions of adult mammalian neocortex that do not normally undergo neurogenesis. It appears that these results are generalizable to other classes of projection neurons (Chen et al., unpublished observations).

Recently, other groups have reported similar and complementary results in hippocampus ${ }^{215}$ and striatum, ${ }^{216,217}$ confirming and further supporting this direction of research. In Nakatomi et al., ${ }^{215}$ an in vivo ischemia model was used in which it was found that massive repopulation of neurons in the CA1 region of the hippocampus is possible following the large-scale elim- ination of these neurons in the CA1 region. It was found that the overwhelming majority of adult-born neurons repopulating the damaged CA1 region originated from a proliferative response in the posterior periventricle, and that this proliferative response could be augmented by infusion of EGF and FGF-2, dramatically increasing the number of neurons able to migrate into and repopulate the damaged CA1 region.

\section{MOLECULAR SIGNALS UNDERLYING INTEGRATION OF TRANSPLANTED AND ENDOGENOUSLY DERIVED NEURONS}

To begin to identify the molecular signals that are responsible for the instructive environment produced by cortex undergoing targeted apoptosis of projection neurons, we analyzed the gene expression of candidate neurotrophins, growth factors, and receptors in regions of targeted neuronal death. We compared gene expression to that of intact adult cortex using Northern blot analysis, in situ hybridization, and immunocytochemical analysis. The genes for BDNF, NT-4/5, and NT-3 are upregulated only in degenerating regions of cortex, specifically during the period of projection neuron apoptosis. ${ }^{42}$ The expression of a variety of other growth factors that are not as developmentally regulated is not altered. These results are in contrast to the less specific, more immediate, and short-lived changes in gene expression observed in response to nonspecific necrotic injuries or seizure-induced injury. Surrounding glia and neurons may change their gene expression in response to activity-dependent changes at their synapses or factors released by degenerating projection neurons. For example, BDNF is upregulated specifically by local interneurons adjacent to degenerating projection neurons. We are currently using PCR-based suppression subtraction hybridization and DNA microarray approaches to examine the expression of other known and novel factors that contribute to the instructive environment formed by cortex undergoing targeted apoptosis of projection neurons. In a complementary manner, we have investigated cellular and molecular controls over the survival ${ }^{218}$ and differentiation $^{219}$ of cortical callosal projection neurons, using cultured FACS-purified neurons of this specific lineage, and analogous analysis of corticospinal motor neurons is ongoing. Furthermore, we have recently identified broad combinatorial programs of gene expression that specify corticospinal motor neuron differentiation (Arlotta et al., unpublished observations), as well as other lineages of cortical projection neurons (Arlotta et al., in preparation). Furthermore, the microenvironmental factors that support the migration, differentiation, and axonal extension of transplanted immature neurons and neural precursors also appear to support and instruct the neuronal differentiation and axon extension of endogenous precursors. 


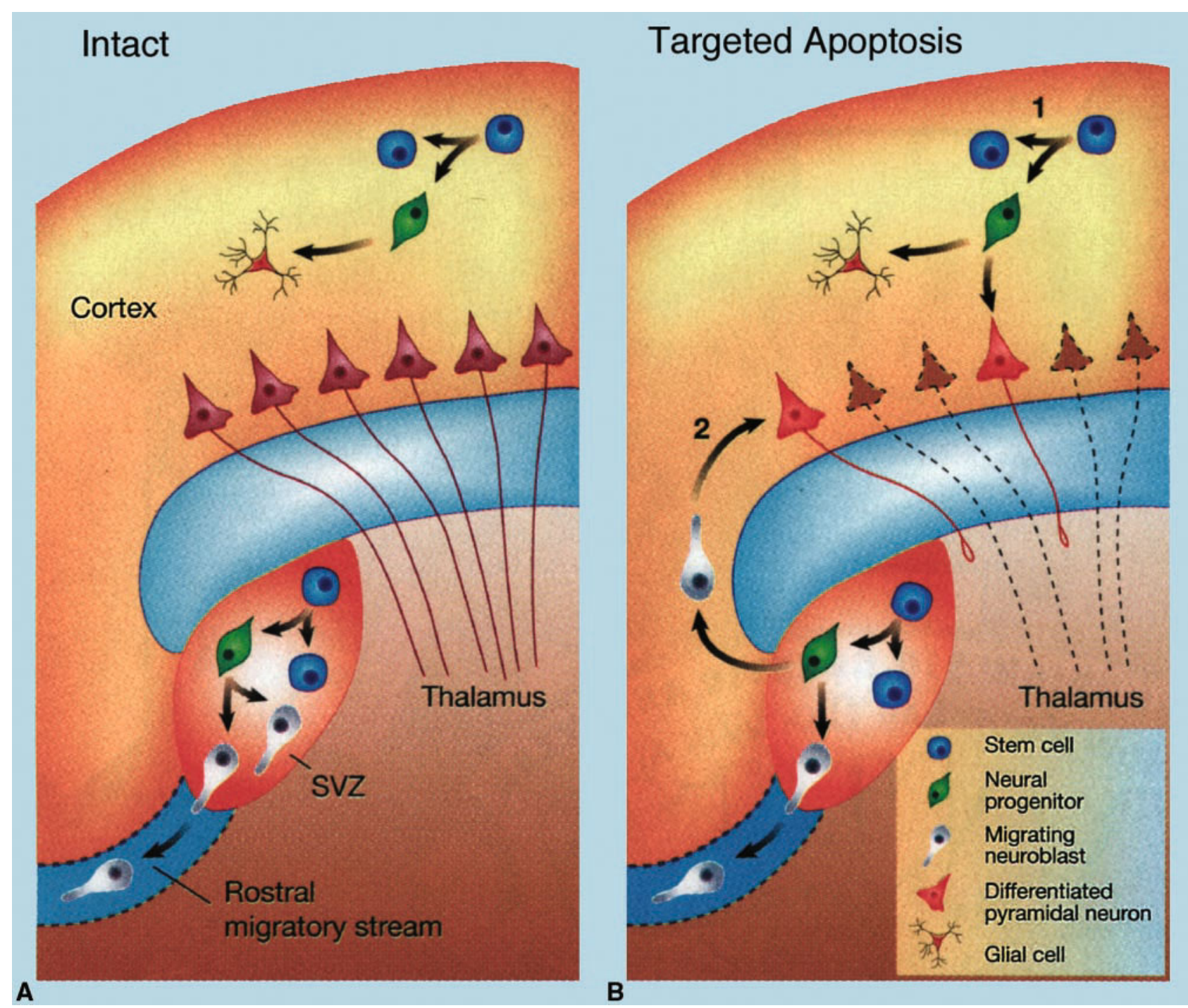

FIG. 1. Induction of neurogenesis in the neocortex of adult mice. Cartoon showing targeted apoptosis of corticothalamic projection neurons and subsequent recruitment of new neurons from endogenous neural precursors, without transplantation, in adult mouse neocortex. A: In intact adult mouse neocortex, endogenous precursors exist in the cortex itself, and in the underlying SVZ. Normally, these precursors produce only glia in cortex. Neurons produced in the anterior SVZ migrate along the rostral migratory stream to the olfactory bulb (not shown). B: When corticothalamic projection neurons are induced to undergo synchronous targeted apoptosis, new migratory neuroblasts are born from endogenous precursors. These cells migrate into cortex, differentiate progressively into fully mature neurons, and a subset send long-distance projections to the thalamus, the appropriate original target of the neurons being replaced. The new neurons appeared to be recruited from SVZ precursors and potentially also from precursors resident in cortex itself. Adapted from Björklund and Lindvall, Nature 405:892-894, 2000, re: Magavi et al., ibid, 405:951-955, 2000. Reprinted with permission from Nature (c) 2000, Macmillan Magazines Ltd.

\section{CONCLUSIONS AND FUTURE PROSPECTS FOR ENDOGENOUS CNS REPAIR}

A better understanding of the cellular and molecular controls over differentiation of neural precursor cells during development and in the adult CNS will be critical for potential cellular therapeutic approaches to repopulating damaged or diseased areas of the nervous system. The future prospect of directing the development and integration of transplanted and endogenous precursors in the adult mammalian brain, toward the replacement of lost neurons or glia, is exciting indeed, and several recent lines of work provide remarkable progress toward this aim. Specifically, recent findings regarding the presence of neural precursors in a number of areas in the adult mammalian brain, ongoing adult mammalian neurogenesis, and the possibility of activating even limited neurogenesis in normally non-neurogenic regions of the adult brain are advancing the field toward the goal of cellular repopulation and repair.

Although constitutive neurogenesis normally occurs in only two areas of the adult mammalian brain (SVZ and dentate gyrus), recent research suggests that it may be possible to manipulate endogenous neural precursors in 
situ to undergo neurogenesis in other regions of the adult brain, toward future neuronal (or oligodendroglial) replacement therapy for neurodegenerative disease and other CNS injury. Multipotent precursors capable of differentiating into neurons, astroglia, and oligodendroglia exist in many regions of the adult brain. These precursors have considerable plasticity and, although they might have limitations in their integration into some areas of the CNS, they appear capable of differentiation into neurons appropriate to a wide variety of regions, when either heterotopically transplanted, or, more recently, recruited in situ. Many adult precursors are capable of migrating long distances, using both tangential and radial forms of migration. Endogenous adult neural precursors are also capable of extending axons significant distances through the adult brain. In addition, in vitro and in vivo experiments have begun to elucidate the responses of endogenous precursors to both growth factors and behavioral manipulations, and are beginning to provide key information toward manipulation of their proliferation and differentiation. For example, recent experiments from our lab have shown that, under appropriate conditions, endogenous precursors can differentiate into neocortical neurons, extend long-distance axonal projections, and survive for long periods of time in regions of the adult brain that do not normally undergo neurogenesis. Other laboratories have recently reported similar results in other systems. Together, these results indicate that there exists a sequence and combination of molecular signals by which neurogenesis can be induced in the adult mammalian cerebral cortex and other regions where it does not normally occur.

These results suggest that neuronal replacement therapies based on manipulation of endogenous precursors may be possible in the future. However, many questions must be answered before neuronal replacement therapies using endogenous precursors become a reality. The multiple signals that are responsible for endogenous precursor division, migration, differentiation, axon extension, and survival will need to be elucidated in order for such therapies to be developed effectively. These challenges also exist for neuronal replacement strategies based on transplantation of precursors, because donor cells, whatever their source, must interact with an extremely complex and intricate mature CNS environment to integrate into the brain. In addition, although it remains an open question, recent results in the field suggest that potential therapies manipulating endogenous precursors in situ would not necessarily be limited to portions of the brain near adult neurogenic regions. It appears that neural precursor cells may be much more widely distributed in the parenchyma of the adult CNS than previously thought, albeit in lower numbers.

Another relatively unexplored theoretical possibility for cellular repopulation in the mammalian CNS is the mechanism used so successfully by urodeles and other amphibians: dedifferentiation of phenotypically mature cells and subsequent repopulation of damaged areas. Although there are not yet data to support directly such dedifferentiation strategies in mammals, theoretically it may be possible to reconstruct complex structures in the adult mammalian CNS as well. Although precursor cells may be widely distributed in the adult mammalian CNS, this population of cells may include precursors that exist as seemingly differentiated cells, expressing mature neural markers, while still retaining the ability to act as precursor cells in response to a highly orchestrated and regulated set of molecular signals. However, with the exception of the SVZ and the inner granular layer of the dentate gyrus, the adult mammalian CNS still appears to be a highly restrictive environment for neuronal production and integration under normal physiological conditions.

Looking forward, it may be possible to induce the cellular repopulation of the diseased brain via specific activation and differentiation of endogenous neural precursors along desired neuronal or glial lineages. Even if multipotent precursors are not located in large numbers outside of normally neurogenic regions of the brain, it may be possible to induce them to proliferate and differentiate from small populations that are more widely distributed throughout the neuraxis. However, this field is just at the beginning of understanding the complex interplay between neural precursor potential and signals in their local microenvironment; much can be learned about precursor heterogeneity and how to take advantage of what may be partial cell-type restriction, permissive and instructive developmental signals, and modulation of specific aspects of neuronal differentiation and survival. Progress over the past decade has been great, and the coming decades promise to offer significant insight into these and other critical issues for the neural repair field.

Acknowledgments: This work was partially supported by grants from the National Institutes of Health (NIH) (NS41590, NS42190, HD28478, MRRC HD18655), the Alzheimer's Association, the Christopher Reeve Paralysis Foundation, the ALS Association, the Human Frontiers Science Program, and the National Science Foundation to J.D.M. J.G.E. was partially supported by a Heart and Stroke Foundation of Canada Fellowship, and by a grant from the Children's Neurobiological Solutions Foundation to J.D.M. B.D.M. was partially supported by a LifeBridge-United Sydney Association Fellowship. S.S.M. was partially supported by an NIH predoctoral training grant and fellowships from the Leopold Schepp Foundation and the Lefler Foundation. P.A. was partially supported by a Wills Foundation Fellowship.

J.G.E. and B.D.M. contributed equally to this manuscript.

\section{REFERENCES}

1. Gates MA, Fricker-Gates RA, Macklis JD. Reconstruction of cortical circuitry. Prog Brain Res 127:115-156, 2000. 
2. Gates MA, Fricker-Gates RA, Magavi SS, Macklis JD. Cellular repair of complex cortical circuitry. The Neuroscientist 6:326337,2000

3. Bjorklund A, Lindvall O. Cell replacement therapies for central nervous system disorders. Nat Neurosci 3:537-544, 2000.

4. Palmer TD, Ray J, Gage FH. FGF-2-responsive neuronal progenitors reside in proliferative and quiescent regions of the adult rodent brain. Mol Cell Neurosci 6:474-486, 1995.

5. Thompson WG. Successful brain grafting. NY Med J 51:701-702, 1890.

6. Tello F. La influencia del neurotropismo en la regeneracion de los centros nerviosos. Trab Lab Invest Biol Univ Madrid 9:123-159, 1911.

7. Ranson SW. Transplantation of the spinal ganglion, with observations on the significance of the complex types of spinal ganglion cells. J Comp Neurol 24:547-588, 1914.

8. Dunn EH. Primary and secondary findings in a series of attempts to transplant cerebral cortex in the albino rat. J Comp Neurol 27:565-582, 1917.

9. Bjorklund A, Stenevi U. Growth of central catecholamine neurones into smooth muscle grafts in the rat mesencephalon. Brain Res 31:1-20, 1971.

10. Das GD, Altman J. Transplanted precursors of nerve cells: their fate in the cerebellums of young rats. Science 173:637-638, 1971.

11. Bjorklund A, Stenevi U.Reconstruction of the nigrostriatal dopamine pathway by intracerebral nigral transplants. Brain Res 177: 555-560, 1979.

12. Stanfield BB, O'Leary DD. Fetal occipital cortical neurones transplanted to the rostral cortex can extend and maintain a pyramidal tract axon. Nature 313:135-137, 1985.

13. O'Leary DD, Stanfield BB. Selective elimination of axons extended by developing cortical neurons is dependent on regional locale: experiments utilizing fetal cortical transplants. $J$ Neurosci 9:2230-2246, 1989.

14. Garnier C, Arnault P, Roger M. Development of the striatal projection from embryonic neurons from the lateral or medial frontal cortex grafted homo- or heterotopically into the medial frontal cortex of newborn rats. Neurosci Lett 235:41-44, 1997.

15. Frantz GD, McConnell SK. Restriction of late cerebral cortical progenitors to an upper-layer fate. Neuron 17:55-61, 1996.

16. McConnell SK, Kaznowski CE. Cell cycle dependence of laminar determination in developing neocortex. Science 254:282-285, 1991.

17. McConnell SK. Fates of visual cortical neurons in the ferret after isochronic and heterochronic transplantation. J Neurosci 8:945974, 1988.

18. Caviness VS Jr, Rakic P. Mechanisms of cortical development: a view from mutations in mice. Annu Rev Neurosci 1:297-326, 1978.

19. Rakic P, Caviness VS Jr. Cortical development: view from neurological mutants two decades later. Neuron 14:1101-1104, 1995.

20. Schlaggar BL, O'Leary DD. Potential of visual cortex to develop an array of functional units unique to somatosensory cortex. Science 252:1556-1560, 1991.

21. Pallas SL, Roe AW, Sur M. Visual projections induced into the auditory pathway of ferrets. I. Novel inputs to primary auditory cortex (AI) from the LP/pulvinar complex and the topography of the MGN-AI projection. J Comp Neurol 298:50-68, 1990.

22. Pallas SL, Sur M. Visual projections induced into the auditory pathway of ferrets. II. Corticocortical connections of primary auditory cortex. J Comp Neurol 337:317-333, 1993.

23. Sur M, Pallas SL, Roe AW. Cross-modal plasticity in cortical development: differentiation and specification of sensory neocortex. Trends Neurosci 13:227-233, 1990.

24. Rakic P. Evolving concepts of cortical radial and areal specification. Prog Brain Res 136:265-280, 2002.

25. Toresson H, Mata de Urquiza A, Fagerstrom C, Perlmann T, Campbell K. Retinoids are produced by glia in the lateral ganglionic eminence and regulate striatal neuron differentiation. Development 126:1317-1326, 1999.

26. Grabowski M, Brundin P, Johansson BB. Fetal neocortical grafts implanted in adult hypertensive rats with cortical infarcts follow- ing a middle cerebral artery occlusion: ingrowth of afferent fibers from the host brain. Exp Neurol 116:105-121, 1992.

27. Dunnett SB. Is it possible to repair the damaged prefrontal cortex by neural tissue transplantation? Prog Brain Res 85:285-297, 1990.

28. Grabowski M, Johansson BB, Brundin P. Survival of fetal neocortical grafts implanted in brain infarcts of adult rats: the influence of postlesion time and age of donor tissue. Exp Neurol 127:126-136, 1994.

29. Sorensen JC, Grabowski M, Zimmer J, Johansson BB. Fetal neocortical tissue blocks implanted in brain infarcts of adult rats interconnect with the host brain. Exp Neurol 138:227-235, 1996.

30. Macklis JD, Madison RD. Neuroblastoma grafts are noninvasively removed within mouse neocortex by selective laser activation of intracellular photolytic chromophore. J Neurosci 11: 2055-2062, 1991.

31. Sheen VL, Dreyer EB, Macklis JD. Calcium-mediated neuronal degeneration following singlet oxygen production. NeuroReport 3:705-708, 1992.

32. Macklis JD. Transplanted neocortical neurons migrate selectively into regions of neuronal degeneration produced by chromophoretargeted laser photolysis. J Neurosci 13:3848-3863, 1993.

33. Sheen VL, Arnold MW, Wang Y, Macklis JD. Neural precursor differentiation following transplantation into neocortex is dependent on intrinsic developmental state and receptor competence. Exp Neurol 158:47-62, 1999.

34. Sheen VL, Macklis JD. Apoptotic mechanisms in targeted neuronal cell death by chromophore-activated photolysis. Exp Neurol 130:67-81, 1994.

35. Sheen VL, Macklis JD. Targeted neocortical cell death in adult mice guides migration and differentiation of transplanted embryonic neurons. J Neurosci 15:8378-8392, 1995.

36. Shin JJ, Fricker-Gates RA, Perez FA, Leavitt BR, Zurakowski D, Macklis JD. Transplanted neuroblasts differentiate appropriately into projection neurons with correct neurotransmitter and receptor phenotype in neocortex undergoing targeted projection neuron degeneration. $J$ Neurosci 20:7404-7416, 2000.

37. Hernit-Grant CS, Macklis JD. Embryonic neurons transplanted to regions of targeted photolytic cell death in adult mouse somatosensory cortex re-form specific callosal projections. Exp Neurol 139:131-142, 1996.

38. Fricker-Gates RA, Shin JJ, Tai CC, Catapano LA, Macklis JD. Late-stage immature neocortical neurons reconstruct interhemispheric connections and form synaptic contacts with increased efficiency in adult mouse cortex undergoing targeted neurodegeneration. J Neurosci 22:4045-4056, 2002.

39. Madison RD, Macklis JD. Noninvasively induced degeneration of neocortical pyramidal neurons in vivo: selective targeting by laser activation of retrogradely transported photolytic chromophore. Exp Neurol 121:153-159, 1993.

40. Leavitt BR, Hernit-Grant CS, Macklis JD. Mature astrocytes transform into transitional radial glia within adult mouse neocortex that supports directed migration of transplanted immature neurons. Exp Neurol 157:43-57, 1999.

41. Snyder EY, Yoon C, Flax JD, Macklis JD. Multipotent neural precursors can differentiate toward replacement of neurons undergoing targeted apoptotic degeneration in adult mouse neocortex. Proc Natl Acad Sci USA 94:11663-11668, 1997.

42. Wang Y, Sheen VL, Macklis JD. Cortical interneurons upregulate neurotrophins in vivo in response to targeted apoptotic degeneration of neighboring pyramidal neurons. Exp Neurol 154:389402, 1998.

43. Davies SJ, Fitch MT, Memberg SP, Hall AK, Raisman G, Silver J. Regeneration of adult axons in white matter tracts of the central nervous system. Nature 390:680-683, 1997.

44. Davies SJ, Goucher DR, Doller C, Silver J. Robust regeneration of adult sensory axons in degenerating white matter of the adult rat spinal cord. J Neurosci 19:5810-5822, 1999.

45. Cadelli DS, Bandtlow CE, Schwab ME. Oligodendrocyte- and myelin-associated inhibitors of neurite outgrowth: their involvement in the lack of CNS regeneration. Exp Neurol 115:189-192, 1992. 
46. Schwab ME. Myelin-associated inhibitors of neurite growth. Exp Neurol 109:2-5, 1990.

47. Schulz MK, Schnell L, Castro AJ, Schwab ME, Kartje GL. Cholinergic innervation of fetal neocortical transplants is increased after neutralization of myelin-associated neurite growth inhibitors. Exp Neurol 149:390-397, 1998.

48. Shewan D, Calaora V, Nielsen P, Cohen J, Rougon G, Moreau H. $\mathrm{mCD} 24$, a glycoprotein transiently expressed by neurons, is an inhibitor of neurite outgrowth. J Neurosci 16:2624-2634, 1996.

49. Z'Graggen WJ, Metz GA, Kartje GL, Thallmair M, Schwab ME. Functional recovery and enhanced corticofugal plasticity after unilateral pyramidal tract lesion and blockade of myelin-associated neurite growth inhibitors in adult rats. J Neurosci 18:47444757, 1998.

50. Chen MS, Huber AB, van der Haar ME, Frank M, Schnell L, Spillmann AA et al. Nogo-A is a myelin-associated neurite outgrowth inhibitor and an antigen for monoclonal antibody IN-1. Nature 403:434-439, 2000.

51. GrandPre T, Nakamura F, Vartanian T, Strittmatter SM. Identification of the Nogo inhibitor of axon regeneration as a Reticulon protein. Nature 403:439-444, 2000.

52. Wang KC, Koprivica V, Kim JA, Sivasankaran R, Guo Y, Neve $\mathrm{RL}$, et al. Oligodendrocyte-myelin glycoprotein is a Nogo receptor ligand that inhibits neurite outgrowth. Nature 417:941-944, 2002.

53. Chen DF, Jhaveri S, Schneider GE. Intrinsic changes in developing retinal neurons result in regenerative failure of their axons. Proc Natl Acad Sci USA 92:7287-7291, 1995.

54. Wictorin K, Brundin P, Sauer H, Lindvall O, Bjorklund A. Long distance directed axonal growth from human dopaminergic mesencephalic neuroblasts implanted along the nigrostriatal pathway in 6-hydroxydopamine lesioned adult rats. J Comp Neurol 323: 475-494, 1992.

55. Rudge JS, Silver J. Inhibition of neurite outgrowth on astroglial scars in vitro. J Neurosci 10:3594-3603, 1990.

56. Lo DC. Neurotrophic factors and synaptic plasticity. Neuron 15 : 979-981, 1995.

57. Behar TN, Li YX, Tran HT, Ma W, Dunlap V, Scott C et al. GABA stimulates chemotaxis and chemokinesis of embryonic cortical neurons via calcium-dependent mechanisms. J Neurosci 16:1808-1818, 1996.

58. Arimatsu Y, Nihonmatsu I, Hirata K, Takiguchi-Hayashi K. Cogeneration of neurons with a unique molecular phenotype in layers $\mathrm{V}$ and VI of widespread lateral neocortical areas in the rat. J Neurosci 14:2020-2031, 1994.

59. Bonni A, Sun Y, Nadal-Vicens M, Bhatt A, Frank DA, Rozovsky I et al. Regulation of gliogenesis in the central nervous system by the JAK-STAT signaling pathway. Science 278:477-483, 1997.

60. Lu N, DiCicco-Bloom E. Pituitary adenylate cyclase-activating polypeptide is an autocrine inhibitor of mitosis in cultured cortical precursor cells. Proc Natl Acad Sci USA 94:3357-3362, 1997.

61. Snyder EY, Macklis JD. Multipotent neural progenitor or stemlike cells may be uniquely suited for therapy for some neurodegenerative conditions. Clin Neurosci 3:310-316, 1995.

62. Snyder EY, Deitcher DL, Walsh C, Arnold-Aldea S, Hartwieg EA, Cepko CL. Multipotent neural cell lines can engraft and participate in development of mouse cerebellum. Cell 68:33-51, 1992.

63. Renfranz PJ, Cunningham MG, McKay RD. Region-specific differentiation of the hippocampal stem cell line HiB5 upon implantation into the developing mammalian brain. Cell 66:713-729, 1991.

64. Altman J, Das GD. Autoradiographic and histological evidence of postnatal hippocampal neurogenesis in rats. J Comp Neurol 124: 319-335, 1965.

65. Altman J. Autoradiographic and histological studies of postnatal neurogenesis. IV. Cell proliferation and migration in the anterior forebrain, with special reference to persisting neurogenesis in the olfactory bulb. J Comp Neurol 137:433-457, 1969.

66. Kaplan MS. Neurogenesis in the 3-month-old rat visual cortex. J Comp Neurol 195:323-338, 1981.
67. Reynolds BA, Weiss S. Generation of neurons and astrocytes from isolated cells of the adult mammalian central nervous system. Science 255:1707-1710, 1992.

68. Richards LJ, Kilpatrick TJ, Bartlett PF. De novo generation of neuronal cells from the adult mouse brain. Proc Natl Acad Sci USA 89:8591-8595, 1992.

69. Kornack DR, Rakic P. The generation, migration, and differentiation of olfactory neurons in the adult primate brain. Proc Natl Acad Sci USA 98:4752-4757, 2001.

70. Pencea V, Bingaman KD, Freedman LJ, Luskin MB. Neurogenesis in the subventricular zone and rostral migratory stream of the neonatal and adult primate forebrain. Exp Neurol 172:1-16, 2001.

71. Kirschenbaum B, Nedergaard M, Preuss A, Barami K, Fraser RA, Goldman SA. In vitro neuronal production and differentiation by precursor cells derived from the adult human forebrain. Cereb Cortex 4:576-589, 1994.

72. Pincus DW, Keyoung HM, Harrison-Restelli C, Goodman RR, Fraser RA, Edgar M et al. Fibroblast growth factor-2/brain-derived neurotrophic factor-associated maturation of new neurons generated from adult human subependymal cells. Ann Neurol 43:576-585, 1998.

73. Bernier PJ, Vinet J, Cossette M, Parent A. Characterization of the subventricular zone of the adult human brain: evidence for the involvement of Bcl-2. Neurosci Res 37:67-78, 2000.

74. Lois C, Alvarez-Buylla A. Long-distance neuronal migration in the adult mammalian brain. Science 264:1145-1148, 1994.

75. Doetsch F, Alvarez-Buylla A. Network of tangential pathways for neuronal migration in adult mammalian brain. Proc Natl Acad Sci USA 93:14895-14900, 1996.

76. Luskin MB, Boone MS. Rate and pattern of migration of lineallyrelated olfactory bulb interneurons generated postnatally in the subventricular zone of the rat. Chem Senses 19:695-714, 1994.

77. Luskin MB. Restricted proliferation and migration of postnatally generated neurons derived from the forebrain subventricular zone. Neuron 11:173-189, 1993.

78. Rousselot P, Lois C, Alvarez-Buylla A. Embryonic (PSA) N$\mathrm{CAM}$ reveals chains of migrating neuroblasts between the lateral ventricle and the olfactory bulb of adult mice. J Comp Neurol 351:51-61, 1995.

79. Sanai N, Tramontin AD, Quinones-Hinojosa A, Barbaro NM, Gupta N, Kunwar S et al. Unique astrocyte ribbon in adult human brain contains neural stem cells but lacks chain migration. Nature 427:740-744, 2004.

80. Mason HA, Ito S, Corfas G. Extracellular signals that regulate the tangential migration of olfactory bulb neuronal precursors: inducers, inhibitors, and repellents. J Neurosci 21:7654-7663, 2001.

81. Hu H, Rutishauser U. A septum-derived chemorepulsive factor for migrating olfactory interneuron precursors. Neuron 16:933940, 1996.

82. Kirschenbaum B, Doetsch F, Lois C, Alvarez-Buylla A. Adult subventricular zone neuronal precursors continue to proliferate and migrate in the absence of the olfactory bulb. $J$ Neurosci 19:2171-2180, 1999.

83. Emsley JG, Hagg T. $\alpha 6 \beta 1$ integrin directs migration of neuronal precursors in adult mouse forebrain. Exp Neurol 183:273-285, 2003.

84. Jacques TS, Relvas JB, Nishimura S, Pytela R, Edwards GM, Streuli $\mathrm{CH}$ et al. Neural precursor cell chain migration and division are regulated through different beta1 integrins. Development 125:3167-3177, 1998.

85. Hu H, Tomasiewicz H, Magnuson T, Rutishauser U. The role of polysialic acid in migration of olfactory bulb interneuron precursors in the subventricular zone. Neuron 16:735-743, 1996.

86. Gates MA, Thomas LB, Howard EM, Laywell ED, Sajin B, Faissner A et al. Cell and molecular analysis of the developing and adult mouse subventricular zone of the cerebral hemispheres. J Comp Neurol 361:249-266, 1995.

87. Garcia-Verdugo JM, Doetsch F, Wichterle H, Lim DA, AlvarezBuylla A. Architecture and cell types of the adult subventricular zone: in search of the stem cells. J Neurobiol 36:234-248, 1998.

88. Law AK, Pencea V, Buck CR, Luskin MB. Neurogenesis and neuronal migration in the neonatal rat forebrain anterior subven- 
tricular zone do not require GFAP-positive astrocytes. Dev Biol 216:622-634, 1999.

89. Liu G, Rao Y. Neuronal migration from the forebrain to the olfactory bulb requires a new attractant persistent in the olfactory bulb. J Neurosci 23:6651-6659, 2003.

90. Caggiano M, Kauer JS, Hunter DD. Globose basal cells are neuronal progenitors in the olfactory epithelium: a lineage analysis using a replication-incompetent retrovirus. Neuron 13:339352,1994

91. Huard JM, Schwob JE. Cell cycle of globose basal cells in rat olfactory epithelium. Dev Dyn 203:17-26, 1995.

92. Graziadei GA, Graziadei PP. Neurogenesis and neuron regeneration in the olfactory system of mammals. II. Degeneration and reconstitution of the olfactory sensory neurons after axotomy. J Neurocytol 8:197-213, 1979.

93. Carr VM, Farbman AI. Ablation of the olfactory bulb up-regulates the rate of neurogenesis and induces precocious cell death in olfactory epithelium. Exp Neurol 115:55-59, 1992.

94. Samanen DW, Forbes WB. Replication and differentiation of olfactory receptor neurons following axotomy in the adult hamster: a morphometric analysis of postnatal neurogenesis. J Comp Neurol 225:201-211, 1984

95. Calof AL, Hagiwara N, Holcomb JD, Mumm JS, Shou J. Neurogenesis and cell death in olfactory epithelium. $J$ Neurobiol 30:67-81, 1996.

96. Barber PC. Neurogenesis and regeneration in the primary olfactory pathway of mammals. Bibl Anat 12-25, 1982.

97. Crews L, Hunter D. Neurogenesis in the olfactory epithelium. Perspect Dev Neurobiol 2:151-161, 1994.

98. Calof AL, Rim PC, Askins KJ, Mumm JS, Gordon MK, Iannuzzelli $\mathrm{P}$ et al. Factors regulating neurogenesis and programmed cell death in mouse olfactory epithelium. Ann NY Acad Sci 855:226229, 1998.

99. Gould E, Tanapat P, McEwen BS, Flugge G, Fuchs E. Proliferation of granule cell precursors in the dentate gyrus of adult monkeys is diminished by stress. Proc Natl Acad Sci USA 95: 3168-3171, 1998.

100. Gould E, Reeves AJ, Fallah M, Tanapat P, Gross CG, Fuchs E. Hippocampal neurogenesis in adult Old World primates. Proc Natl Acad Sci USA 96:5263-5267, 1999.

101. Kornack DR, Rakic P. Continuation of neurogenesis in the hippocampus of the adult macaque monkey. Proc Natl Acad Sci USA 96:5768-5773, 1999.

102. Eriksson PS, Perfilieva E, Bjork-Eriksson T, Alborn AM, Nordborg C, Peterson DA et al. Neurogenesis in the adult human hippocampus. Nat Med 4:1313-1317, 1998.

103. Stanfield BB, Trice JE. Evidence that granule cells generated in the dentate gyrus of adult rats extend axonal projections. Exp Brain Res 72:399-406, 1988.

104. Hastings NB, Gould E. Rapid extension of axons into the CA3 region by adult-generated granule cells. J Comp Neurol [Erratum 415:144, 1999] 413:146-154, 1999.

105. Markakis EA, Gage FH. Adult-generated neurons in the dentate gyrus send axonal projections to field CA 3 and are surrounded by synaptic vesicles. J Comp Neurol 406:449-460, 1999.

106. Gage FH, Kempermann G, Palmer TD, Peterson DA, Ray J. Multipotent progenitor cells in the adult dentate gyrus. J Neurobiol 36:249-266, 1998.

107. van Praag H, Schinder AF, Christie BR, Toni N, Palmer TD, Gage FH. Functional neurogenesis in the adult hippocampus. Nature 415:1030-1034, 2002.

108. Lowenstein DH, Arsenault L. The effects of growth factors on the survival and differentiation of cultured dentate gyrus neurons. J Neurosci 16:1759-1769, 1996.

109. Kukekov VG, Laywell ED, Suslov O, Davies K, Scheffler B, Thomas LB et al. Multipotent stem/progenitor cells with similar properties arise from two neurogenic regions of adult human brain. Exp Neurol 156:333-344, 1999.

110. Roy NS, Wang S, Jiang L, Kang J, Benraiss A, Harrison-Restelli $\mathrm{C}$ et al. In vitro neurogenesis by progenitor cells isolated from the adult human hippocampus. Nat Med 6:271-277, 2000.
111. Kuhn HG, Dickinson-Anson H, Gage FH. Neurogenesis in the dentate gyrus of the adult rat: age-related decrease of neuronal progenitor proliferation. $J$ Neurosci 16:2027-2033, 1996.

112. Cameron HA, McKay RD. Restoring production of hippocampal neurons in old age. Nat Neurosci 2:894-897, 1999.

113. Montaron MF, Petry KG, Rodriguez JJ, Marinelli M, Aurousseau $\mathrm{C}$, Rougon $\mathrm{G}$ et al. Adrenalectomy increases neurogenesis but not PSA-NCAM expression in aged dentate gyrus. Eur $J$ Neurosci 11:1479-1485, 1999.

114. Bengzon J, Kokaia Z, Elmer E, Nanobashvili A, Kokaia M, Lindvall O. Apoptosis and proliferation of dentate gyrus neurons after single and intermittent limbic seizures. Proc Natl Acad Sci USA 94:10432-10437, 1997.

115. Parent JM, Yu TW, Leibowitz RT, Geschwind DH, Sloviter RS, Lowenstein DH. Dentate granule cell neurogenesis is increased by seizures and contributes to aberrant network reorganization in the adult rat hippocampus. $J$ Neurosci 17:3727-3738, 1997.

116. Huang L, Cilio MR, Silveira DC, McCabe BK, Sogawa Y, Stafstrom CE et al. Long-term effects of neonatal seizures: a behavioral, electrophysiological, and histological study. Brain Res Dev Brain Res 118:99-107, 1999.

117. Represa A, Niquet J, Pollard H, Ben-Ari Y. Cell death, gliosis, and synaptic remodeling in the hippocampus of epileptic rats. J Neurobiol 26:413-425, 1995.

118. Parent JM, Janumpalli S, McNamara JO, Lowenstein DH. Increased dentate granule cell neurogenesis following amygdala kindling in the adult rat. Neurosci Lett 247:9-12, 1998.

119. Whittington DL, Woodruff ML, Baisden RH. The time-course of trimethyltin-induced fiber and terminal degeneration in hippocampus. Neurotoxicol Teratol 11:21-33, 1989.

120. Magloczky Z, Freund TF. Selective neuronal death in the contralateral hippocampus following unilateral kainate injections into the CA3 subfield. Neuroscience 56:317-335, 1993.

121. Pollard H, Charriaut-Marlangue C, Cantagrel S, Represa A, Robain O, Moreau J et al. Kainate-induced apoptotic cell death in hippocampal neurons. Neuroscience 63:7-18, 1994.

122. Gould E, Tanapat P. Lesion-induced proliferation of neuronal progenitors in the dentate gyrus of the adult rat. Neuroscience 80:427-436, 1997.

123. Derrick BE, York AD, Martinez JL Jr. Increased granule cell neurogenesis in the adult dentate gyrus following mossy fiber stimulation sufficient to induce long-term potentiation. Brain Res 857:300-307, 2000.

124. Kempermann G, Kuhn HG, Gage FH. More hippocampal neurons in adult mice living in an enriched environment. Nature 386:493495, 1997.

125. van Praag H, Christie BR, Sejnowski TJ, Gage FH. Running enhances neurogenesis, learning, and long-term potentiation in mice. Proc Natl Acad Sci USA 96:13427-13431, 1999.

126. van Praag H, Kempermann G, Gage FH. Running increases cell proliferation and neurogenesis in the adult mouse dentate gyrus. Nat Neurosci 2:266-270, 1999.

127. Gould E, Beylin A, Tanapat P, Reeves A, Shors TJ. Learning enhances adult neurogenesis in the hippocampal formation. Nat Neurosci 2:260-265, 1999.

128. Gould E, McEwen BS, Tanapat P, Galea LA, Fuchs E. Neurogenesis in the dentate gyrus of the adult tree shrew is regulated by psychosocial stress and NMDA receptor activation. $J$ Neurosci 17:2492-2498, 1997.

129. Tanapat P, Galea LA, Gould E. Stress inhibits the proliferation of granule cell precursors in the developing dentate gyrus. Int $J$ Dev Neurosci 16:235-239, 1998.

130. Aberg MA, Aberg ND, Hedbacker H, Oscarsson J, Eriksson PS. Peripheral infusion of IGF-I selectively induces neurogenesis in the adult rat hippocampus. $J$ Neurosci 20:2896-2903, 2000.

131. Trejo JL, Carro E, Torres-Aleman I. Circulating insulin-like growth factor I mediates exercise-induced increases in the number of new neurons in the adult hippocampus. J Neurosci 21: 1628-1634, 2001.

132. Gould E, Cameron HA, Daniels DC, Woolley CS, McEwen BS. Adrenal hormones suppress cell division in the adult rat dentate gyrus. J Neurosci 12:3642-3650, 1992. 
133. Chen G, Rajkowska G, Du F, Seraji-Bozorgzad N, Manji HK. Enhancement of hippocampal neurogenesis by lithium. J Neurochem 75:1729-1734, 2000.

134. Malberg JE, Eisch AJ, Nestler EJ, Duman RS. Chronic antidepressant treatment increases neurogenesis in adult rat hippocampus. J Neurosci 20:9104-9110, 2000.

135. Santarelli L, Saxe M, Gross C, Surget A, Battaglia F, Dulawa S et al. Requirement of hippocampal neurogenesis for the behavioral effects of antidepressants. Science 301:805-809, 2003.

136. Kempermann G, van Praag H, Gage FH. Activity-dependent regulation of neuronal plasticity and self repair. Prog Brain Res 127:35-48, 2000.

137. Suhonen JO, Peterson DA, Ray J, Gage FH. Differentiation of adult hippocampus-derived progenitors into olfactory neurons in vivo. Nature 383:624-627, 1996.

138. Nishida A, Takahashi M, Tanihara H, Nakano I, Takahashi JB, Mizoguchi A et al. Incorporation and differentiation of hippocampus-derived neural stem cells transplanted in injured adult rat retina. Invest Ophthalmol Vis Sci 41:4268-4274, 2000.

139. Young MJ, Ray J, Whiteley SJ, Klassen H, Gage FH. Neuronal differentiation and morphological integration of hippocampal progenitor cells transplanted to the retina of immature and mature dystrophic rats. Mol Cell Neurosci 16:197-205, 2000.

140. Shors TJ, Miesegaes G, Beylin A, Zhao M, Rydel T, Gould E. Neurogenesis in the adult is involved in the formation of trace memories. Nature 410:372-376, 2001.

141. Jacobs BL, Praag H, Gage FH. Adult brain neurogenesis and psychiatry: a novel theory of depression. Mol Psychiatry 5:262$269,2000$.

142. Duman RS, Malberg J, Thome J. Neural plasticity to stress and antidepressant treatment. Biol Psychiatry 46:1181-1191, 1999.

143. Brezun JM, Daszuta A. Depletion in serotonin decreases neurogenesis in the dentate gyrus and the subventricular zone of adult rats. Neuroscience 89:999-1002, 1999.

144. Gage FH, Coates PW, Palmer TD, Kuhn HG, Fisher LJ, Suhonen $\mathrm{JO}$ et al. Survival and differentiation of adult neuronal progenitor cells transplanted to the adult brain. Proc Natl Acad Sci USA 92:11879-11883, 1995.

145. Palmer TD, Takahashi J, Gage FH. The adult rat hippocampus contains primordial neural stem cells. Mol Cell Neurosci 8:389404, 1997.

146. Seaberg RM, van der Kooy D. Adult rodent neurogenic regions: the ventricular subependyma contains neural stem cells, but the dentate gyrus contains restricted progenitors. J Neurosci 22:1784-1793, 2002.

147. Magavi SS, Leavitt BR, Macklis JD. Induction of neurogenesis in the neocortex of adult mice. Nature 405:951-955, 2000.

148. Gould E, Reeves AJ, Graziano MS, Gross CG. Neurogenesis in the neocortex of adult primates. Science 286:548-552, 1999.

149. Gould E, Vail N, Wagers M, Gross CG. Adult-generated hippocampal and neocortical neurons in macaques have a transient existence. Proc Natl Acad Sci USA 98:10910-10917, 2001.

150. Ehninger D, Kempermann G. Regional effects of wheel running and environmental enrichment on cell genesis and microglia proliferation in the adult murine neocortex. Cereb Cortex 13:845851,2003

151. Kornack DR, Rakic P. Cell proliferation without neurogenesis in adult primate neocortex. Science 294:2127-2130, 2001.

152. Koketsu D, Mikami A, Miyamoto Y, Hisatsune T. Nonrenewal of neurons in the cerebral neocortex of adult macaque monkeys. J Neurosci 23:937-942, 2003.

153. Zhao M, Momma S, Delfani K, Carlen M, Cassidy RM, Johansson $\mathrm{CB}$ et al. Evidence for neurogenesis in the adult mammalian substantia nigra. Proc Natl Acad Sci USA 100:7925-7930, 2003.

154. Palmer TD, Markakis EA, Willhoite AR, Safar F, Gage FH. Fibroblast growth factor-2 activates a latent neurogenic program in neural stem cells from diverse regions of the adult CNS. J Neurosci 19:8487-8497, 1999.

155. Weiss S, Dunne C, Hewson J, Wohl C, Wheatley M, Peterson AC et al. Multipotent CNS stem cells are present in the adult mammalian spinal cord and ventricular neuroaxis. J Neurosci 16: 7599-7609, 1996.
156. Shihabuddin LS, Ray J, Gage FH. FGF-2 is sufficient to isolate progenitors found in the adult mammalian spinal cord. Exp Neurol 148:577-586, 1997.

157. Tropepe V, Coles BL, Chiasson BJ, Horsford DJ, Elia AJ, McInnes RR et al. Retinal stem cells in the adult mammalian eye Science 287:2032-2036, 2000.

158. Brewer GJ. Regeneration and proliferation of embryonic and adult rat hippocampal neurons in culture. Exp Neurol 159:237247, 1999.

159. Gu W, Brannstrom T, Wester P. Cortical neurogenesis in adult rats after reversible photothrombotic stroke. J Cereb Blood Flow Metab 20:1166-1173, 2000.

160. Yang Y, Geldmacher DS, Herrup K. DNA replication precedes neuronal cell death in Alzheimer's disease. $J$ Neurosci 21:26612668,2001

161. Johansson CB, Momma S, Clarke DL, Risling M, Lendahl U, Frisen J. Identification of a neural stem cell in the adult mammalian central nervous system. Cell 96:25-34, 1999.

162. Chiasson BJ, Tropepe V, Morshead CM, van der Kooy D. Adult mammalian forebrain ependymal and subependymal cells demonstrate proliferative potential, but only subependymal cells have neural stem cell characteristics. J Neurosci 19:4462-4471, 1999.

163. Doetsch F, Caille I, Lim DA, Garcia-Verdugo JM, AlvarezBuylla A. Subventricular zone astrocytes are neural stem cells in the adult mammalian brain. Cell 97:703-716, 1999.

164. Seri B, Garcia-Verdugo JM, McEwen BS, Alvarez-Buylla A. Astrocytes give rise to new neurons in the adult mammalian hippocampus. J Neurosci 21:7153-7160, 2001.

165. Laywell ED, Rakic P, Kukekov VG, Holland EC, Steindler DA. Identification of a multipotent astrocytic stem cell in the immature and adult mouse brain. Proc Natl Acad Sci USA 97:13883-13888, 2000.

166. Imura T, Kornblum HI, Sofroniew MV. The predominant neural stem cell isolated from postnatal and adult forebrain but not early embryonic forebrain expresses GFAP. J Neurosci 23:2824-2832, 2003.

167. Morshead CM, Garcia AD, Sofroniew MV, van Der Kooy D. The ablation of glial fibrillary acidic protein-positive cells from the adult central nervous system results in the loss of forebrain neural stem cells but not retinal stem cells. Eur J Neurosci 18:76-84, 2003.

168. Whittemore SR, Morassutti DJ, Walters WM, Liu RH, Magnuson DS. Mitogen and substrate differentially affect the lineage restriction of adult rat subventricular zone neural precursor cell populations. Exp Cell Res 252:75-95, 1999.

169. Gritti A, Cova L, Parati EA, Galli R, Vescovi AL. Basic fibroblast growth factor supports the proliferation of epidermal growth factor-generated neuronal precursor cells of the adult mouse CNS Neurosci Lett 185:151-154, 1995.

170. Gritti A, Frolichsthal-Schoeller P, Galli R, Parati EA, Cova L, Pagano SF et al. Epidermal and fibroblast growth factors behave as mitogenic regulators for a single multipotent stem cell-like population from the subventricular region of the adult mouse forebrain. J Neurosci 19:3287-3297, 1999.

171. Gritti A, Parati EA, Cova L, Frolichsthal P, Galli R, Wanke E et al. Multipotential stem cells from the adult mouse brain proliferate and self-renew in response to basic fibroblast growth factor J Neurosci 16:1091-1100, 1996.

172. Gross RE, Mehler MF, Mabie PC, Zang Z, Santschi L, Kessler JA. Bone morphogenetic proteins promote astroglial lineage commitment by mammalian subventricular zone progenitor cells. Neuron 17:595-606, 1996.

173. Williams BP, Park JK, Alberta JA, Muhlebach SG, Hwang GY, Roberts TM et al. A PDGF-regulated immediate early gene response initiates neuronal differentiation in ventricular zone progenitor cells. Neuron 18:553-562, 1997.

174. Arsenijevic Y, Weiss S. Insulin-like growth factor-I is a differentiation factor for postmitotic CNS stem cell-derived neuronal precursors: distinct actions from those of brain-derived neurotrophic factor. $J$ Neurosci 18:2118-2128, 1998.

175. Kirschenbaum B, Goldman SA. Brain-derived neurotrophic factor promotes the survival of neurons arising from the adult rat 
forebrain subependymal zone. Proc Natl Acad Sci USA 92:210214, 1995.

176. Goldman SA, Kirschenbaum B, Harrison-Restelli C, Thaler HT Neuronal precursors of the adult rat subependymal zone persist into senescence, with no decline in spatial extent or response to BDNF. J Neurobiol 32:554-566, 1997.

177. Ahmed S, Reynolds BA, Weiss S. BDNF enhances the differentiation but not the survival of CNS stem cell-derived neuronal precursors. J Neurosci 15:5765-5778, 1995.

178. Craig CG, Tropepe V, Morshead CM, Reynolds BA, Weiss S, van der Kooy D. In vivo growth factor expansion of endogenous subependymal neural precursor cell populations in the adult mouse brain. J Neurosci 16:2649-2658, 1996.

179. Kuhn HG, Winkler J, Kempermann G, Thal LJ, Gage FH. Epidermal growth factor and fibroblast growth factor-2 have different effects on neural progenitors in the adult rat brain. $J$ Neurosci 17:5820-5829, 1997.

180. Emsley JG, Hagg T. Endogenous and exogenous ciliary neurotrophic factor enhances forebrain neurogenesis in adult mice. Exp Neurol 183:298-310, 2003.

181. Wagner JP, Black IB, DiCicco-Bloom E. Stimulation of neonatal and adult brain neurogenesis by subcutaneous injection of basic fibroblast growth factor. J Neurosci 19:6006-6016, 1999.

182. Zigova T, Pencea V, Wiegand SJ, Luskin MB. Intraventricular administration of BDNF increases the number of newly generated neurons in the adult olfactory bulb. Mol Cell Neurosci 11:234245, 1998

183. Benraiss A, Chmielnicki E, Lerner K, Roh D, Goldman SA. Adenoviral brain-derived neurotrophic factor induces both neostriatal and olfactory neuronal recruitment from endogenous progenitor cells in the adult forebrain. $J$ Neurosci 21:6718-6731, 2001.

184. Pencea V, Bingaman KD, Wiegand SJ, Luskin MB. Infusion of brain-derived neurotrophic factor into the lateral ventricle of the adult rat leads to new neurons in the parenchyma of the striatum, septum, thalamus, and hypothalamus. $J$ Neurosci 21:6706-6717, 2001.

185. Lim DA, Fishell GJ, Alvarez-Buylla A. Postnatal mouse subventricular zone neuronal precursors can migrate and differentiate within multiple levels of the developing neuraxis. Proc Natl Acad Sci USA 94:14832-14836, 1997.

186. Herrera DG, Garcia-Verdugo JM, Alvarez-Buylla A. Adult-derived neural precursors transplanted into multiple regions in the adult brain. Ann Neurol 46:867-877, 1999.

187. Morshead CM, Benveniste P, Iscove NN, van der Kooy D. Hematopoietic competence is a rare property of neural stem cells that may depend on genetic and epigenetic alterations. Nat Med $8: 268-273,2002$.

188. Clarke DL, Johansson CB, Wilbertz J, Veress B, Nilsson E, Karlstrom $\mathrm{H}$ et al. Generalized potential of adult neural stem cells. Science 288:1660-1663, 2000.

189. Malatesta P, Hack MA, Hartfuss E, Kettenmann H, Klinkert W, Kirchhoff $F$ et al. Neuronal or glial progeny. Regional differences in radial glia fate. Neuron 37:751-764, 2003.

190. Hartfuss E, Galli R, Heins N, Gotz M. Characterization of CNS precursor subtypes and radial glia. Dev Biol 229:15-30, 2001.

191. Noctor SC, Flint AC, Weissman TA, Dammerman RS, Kriegstein AR. Neurons derived from radial glial cells establish radial units in neocortex. Nature 409:714-720, 2001.

192. Tamamaki N, Nakamura K, Okamoto K, Kaneko T. Radial glia is a progenitor of neocortical neurons in the developing cerebral cortex. Neurosci Res 41:51-60, 2001.

193. Gotz M, Stoykova A, Gruss P. Pax6 controls radial glia differentiation in the cerebral cortex. Neuron 21:1031-1044, 1998.

194. Donoghue MJ, Rakic P. Molecular gradients and compartments in the embryonic primate cerebral cortex. Cereb Cortex 9:586-600, 1999.

195. Heins N, Malatesta P, Cecconi F, Nakafuku M, Tucker KL, Hack MA et al. Glial cells generate neurons: the role of the transcription factor Pax6. Nat Neurosci 5:308-315, 2002.

196. Campbell K, Gotz M. Radial glia: multi-purpose cells for vertebrate brain development. Trends Neurosci 25:235-238, 2002.
197. Sanchez-Ramos J, Song S, Cardozo-Pelaez F, Hazzi C, Stedeford $\mathrm{T}$, Willing A et al. Adult bone marrow stromal cells differentiate into neural cells in vitro. Exp Neurol 164:247-256, 2000.

198. Woodbury D, Schwarz EJ, Prockop DJ, Black IB. Adult rat and human bone marrow stromal cells differentiate into neurons. J Neurosci Res 61:364-370, 2000.

199. Brazelton TR, Rossi FM, Keshet GI, Blau HM. From marrow to brain: expression of neuronal phenotypes in adult mice. Science 290:1775-1779, 2000.

200. Mezey E, Chandross KJ, Harta G, Maki RA, McKercher SR. Turning blood into brain: cells bearing neuronal antigens generated in vivo from bone marrow. Science 290:1779-1782, 2000.

201. Priller J, Persons DA, Klett FF, Kempermann G, Kreutzberg GW, Dirnagl U. Neogenesis of cerebellar Purkinje neurons from genemarked bone marrow cells in vivo. J Cell Biol 155:733-738, 2001.

202. Chen J, Li Y, Wang L, Zhang Z, Lu D, Lu M et al. Therapeutic benefit of intravenous administration of bone marrow stromal cells after cerebral ischemia in rats. Stroke 32:1005-1011, 2001.

203. Li Y, Chen J, Wang L, Lu M, Chopp M. Treatment of stroke in rat with intracarotid administration of marrow stromal cells. $\mathrm{Neu}$ rology 56:1666-1672, 2001.

204. Chen X, Katakowski M, Li Y, Lu D, Wang L, Zhang L et al. Human bone marrow stromal cell cultures conditioned by traumatic brain tissue extracts: growth factor production. $J$ Neurosci Res 69:687-691, 2002.

205. Li Y, Chen J, Chen XG, Wang L, Gautam SC, Xu YX et al. Human marrow stromal cell therapy for stroke in rat: neurotrophins and functional recovery. Neurology 59:514-523, 2002.

206. Hess DC, Hill WD, Martin-Studdard A, Carroll J, Brailer J, Carothers J. Bone marrow as a source of endothelial cells and NeuN-expressing cells after stroke. Stroke 33:1362-1368, 2002.

207. Chen J, Zhang ZG, Li Y, Wang L, Xu YX, Gautam SC et al. Intravenous administration of human bone marrow stromal cells induces angiogenesis in the ischemic boundary zone after stroke in rats. Circ Res 92:692-699, 2003.

208. Castro RF, Jackson KA, Goodell MA, Robertson CS, Liu H, Shine HD. Failure of bone marrow cells to transdifferentiate into neural cells in vivo. Science 297:1299, 2002.

209. Wagers AJ, Sherwood RI, Christensen JL, Weissman IL. Little evidence for developmental plasticity of adult hematopoietic stem cells. Science 297:2256-2259, 2002.

210. Vallieres L, Sawchenko PE. Bone marrow-derived cells that populate the adult mouse brain preserve their hematopoietic identity. J Neurosci 23:5197-5207, 2003.

211. Vassilopoulos G, Wang PR, Russell DW. Transplanted bone marrow regenerates liver by cell fusion. Nature 422:901-904, 2003.

212. Alvarez-Dolado M, Pardal R, Garcia-Verdugo JM, Fike JR, Lee $\mathrm{HO}$, Pfeffer K et al. Fusion of bone-marrow-derived cells with Purkinje neurons, cardiomyocytes and hepatocytes. Nature 425: 968-973, 2003.

213. Wang X, Willenbring H, Akkari Y, Torimaru Y, Foster M, AlDhalimy $\mathrm{M}$ et al. Cell fusion is the principal source of bonemarrow-derived hepatocytes. Nature 422:897-901, 2003.

214. Scharff C, Kirn JR, Grossman M, Macklis JD, Nottebohm F Targeted neuronal death affects neuronal replacement and vocal behavior in adult songbirds. Neuron 25:481-492, 2000.

215. Nakatomi H, Kuriu T, Okabe S, Yamamoto S, Hatano O, Kawahara $\mathrm{N}$ et al. Regeneration of hippocampal pyramidal neurons after ischemic brain injury by recruitment of endogenous neural progenitors. Cell 110:429-441, 2002.

216. Parent JM, Vexler ZS, Gong C, Derugin N, Ferriero DM. Rat forebrain neurogenesis and striatal neuron replacement after focal stroke. Ann Neurol 52:802-813, 2002.

217. Arvidsson A, Collin T, Kirik D, Kokaia Z, Lindvall O. Neuronal replacement from endogenous precursors in the adult brain after stroke. Nat Med 8:963-970, 2002.

218. Catapano LA, Arnold MW, Perez FA, Macklis JD. Specific neurotrophic factors support the survival of cortical projection neurons at distinct stages of development. $J$ Neurosci 21:8863-8872, 2001.

219. Catapano LA, Arlotta P, Cage TA, Macklis JD. Stage-specific and opposing roles of BDNF, NT-3, and bFGF in differentiation of purified callosal projection neurons toward cellular repair of complex circuitry. Eur J Neurosci 19:2421-2434, 2004. 